See discussions, stats, and author profiles for this publication at: https://www.researchgate.net/publication/272306626

\title{
The Problem of the Divided Majority: Preference Aggregation Under Uncertainty
}

Article in Journal of Economic Behavior \& Organization · October 2016 Dol: 10.1016/.j.jebo.2016.10.022

CITATIONS

4

1 author:

(3.) Georg D. Granic

University of Antwerp

17 PUBLICATIONS 72 CITATIONS

SEE PROFILE

Some of the authors of this publication are also working on these related projects:

Measuring voters' preferences View project

\section{READS}

81 


\title{
The problem of the divided majority: Preference aggregation under uncertainty
}

\author{
Đura-Georg Granić ${ }^{* \dagger}$
}

November 8, 2016

\begin{abstract}
This paper reports on the results of a series of experimental laboratory elections. The novelty of the design allows me to study the extent to which voting methods defeat the Condorcet loser and elect the Condorcet winner in a repeated-game, divided majority setting. I assess and compare the performance of three voting mechanisms, Approval Voting, Borda Count, and Plurality Voting under two information structures. Voters either know the preference structure in the electorate or hold no information regarding other voters' preferences. With enough experience, the number of elections won by the Condorcet loser is fairly low across voting methods and information structures. Approval Voting and Borda Count dissolve information imperfections efficiently and allow voters to implement the Condorcet winner, independently of the underlying information structure. The frequency with which the Condorcet winner is elected under Plurality Voting crucially depends on available information. When voters are uninformed about the preference structure in the electorate, Plurality Voting fails to implement the Condorcet winner. This is costly and decreases total welfare.
\end{abstract}

Keywords: Divided majority, Approval Voting, Borda Count, Plurality Voting, Uncertainty JEL-classification: D70, D71, D80

\footnotetext{
*Department of Applied Economics, Erasmus School of Economics (Netherlands). Email: granic@ese.eur.nl

${ }^{\dagger}$ The author thanks Carlos Alós-Ferrer, Tanja Artiga González, Steven Brams, Michael Bechtel, Urs Fischbacher, Torsten Jochem, Johannes Kern, Aniol Llorente-Saguer, Rebecca Morton, Heinrich Ursprung, and Alexander K. Wagner. The author also thanks seminar participants at the University of Cologne, HumboldtUniversität zu Berlin, University of Konstanz, and University of St. Gallen, and the participants at the UECE Lisbon Meeting in Game Theory and Applications (2011), the Economic Science Association European Conference in Cologne (2012), the Games 2012: 4th World Meeting of the Game Theory Society in Istanbul (2012), the International Meeting on Experimental and Behavioral Economics in Benicassim (2012), the 5th International Doctoral Meeting of Montpelier in Economics, Management and Finance in Montpelier (2013), and the Meeting of COST Action IC1205 on Computational Social Choice, in Oxford (2013) for helpful comments and discussions. The author also gratefully acknowledges financial support from the German Research Foundation (DFG) through research project AL-1169/2-1 carried out at the Department of Economics, University of Cologne, Germany. Part of the draft was written while the author was visiting New York University, whose hospitality is gratefully acknowledged.
} 


\section{Contents}

1 Introduction $\quad 3$

2 Theoretical background and hypotheses $\quad 5$

2.1 The voting game . . . . . . . . . . . . . . . . . 5

2.2 Motivation and main research question . . . . . . . . . . . . . 7

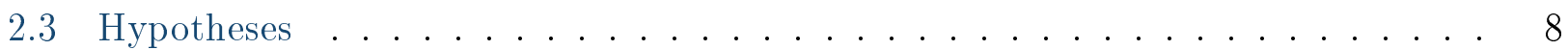

3 Experimental design $\quad 10$

3.1 Procedures . . . . . . . . . . . . . . . . . . 10

4 Aggregated election results $\quad 11$

4.1 Summary of election results . . . . . . . . . . . . . . . . . 11

4.2 Main hypotheses and results . . . . . . . . . . . . . . . 12

4.3 Summary of the main findings . . . . . . . . . . . . . . . 17

5 Individual voting behavior $\quad 18$

5.1 Approval Voting . . . . . . . . . . . . . . . . 18

5.2 Plurality Voting . . . . . . . . . . . . . . . . . . . 18

5.3 Borda Count . . . . . . . . . . . . . . . . . . 19

5.4 The importance of strategic considerations . . . . . . . . . . . . . 20

6 Conclusion $\quad 23$

$\begin{array}{lr}\text { A Additional tables } & 28\end{array}$

$\begin{array}{ll}\text { B Experimental materials } & 31\end{array}$

B.1 Instructions full information: English . . . . . . . . . . . . . . 31

B.2 Instructions full information: German . . . . . . . . . . . . . . . . 33

B.3 Instructions no information . . . . . . . . . . . . 36

B.4 Decision screens . . . . . . . . . . . . . . . 36

C Supplementary online material: additional results and tables 39

C.1 Non-parametric tests main hypothesis for first series of elections . . . . . . . . 39

C.2 Iterative elimination of weakly dominated strategies . . . . . . . . . . 40

C.3 Additional tables . . . . . . . . . . . . . . . . . . . . 40 


\section{Introduction}

In divided majority problems (DMPs) a majority of voters is divided in their support between several similarly appealing alternatives (parties, candidates, etc). If the majority is split, a socially undesirable alternative, preferred by the minority, will win the election. Such an alternative constitutes a Condorcet loser, an alternative that is defeated by every other alternative in a pairwise race (a Condorcet winner is able to defeat every other alternative in a two-way race, see e.g. Black, 1958, for a discussion of both concepts). Failures to defeat the Condorcet loser in DMPs pose a major threat for democratic practice as they compromise the wishes of the voters. They derail the democratic process by undermining the legitimacy of appointed leaders. ${ }^{1}$

Voting mechanisms should satisfactorily deal with two important issues in the context of DMPs. First, they should defeat Condorcet losers. Second, they should elect the best among several running alternatives. While the existing literature on DMPs has primarily focused on the first issue (see, e.g., Forsythe et al., 1996; Gerber et al., 1998; Morton and Rietz, 2007), the second motive has received only little attention thus far and is typically overlooked (Bouton and Castanheira, 2012; Bouton et al., 2016, form a notable exception).

The aim of this paper is to bridge this gap and investigate the extent to which different voting mechanisms defeat Condorcet losers and elect Condorcet winners. Specifically, I assess and compare the performance of three voting mechanisms, Approval Voting (AV), Borda Count (BC), and Plurality Voting (PV) in a series of laboratory elections. AV and BC are multi-vote methods which offer voters additional opportunities to express their preferences. The design of the experiment introduces two important novelties with regard to existing literature. First, I study a novel, repeated-game DMP setting. To defeat the Condorcet loser the majority has three (other) alternatives available to coordinate on. However, one of the alternatives is clearly the most desirable one: it constitutes a unique Condorcet winner, a consensus alternative acceptable to the minority, and maximizes total surplus for society. Second, I consider an information structure where voters only observe past election outcomes and do not know the preference distribution in the electorate. The central question that I investigate is how information about other voters' preferences affects voters' ability to implement the efficient Condorcet winner.

Abundant evidence suggests that voters display a low level of informedness about politics and eligible candidates (Sears and Kinder, 1985). They rely on other sources of the electoral process (e.g., polls, media coverage, campaign spending) to procure enough information to guide their choices (e.g. Wittman, 1989; Lau and Redlawsk, 1997; Sinclair and Plott, 2012). The electoral process itself is driven by the voting mechanism employed and focuses on the alternatives expected to do well. These alternatives will perform well in polls, attract the attention of the media, and gather more funds for their campaigns. Thus, if voting mechanisms tend to favor polarizing choices over consensus options, compromise alternatives who share a broad support in the electorate might go unnoticed to the public. The presence of this link between voting mechanisms and the electoral process implies that, even for a fixed set of

1 Failures to defeat Condorcet losers in DMPs have been frequently observed in elections based on or involving Plurality Voting. The United States Presidential Election in 1912 (analyzed in Riker, 1982) is one of many infamous examples. Failing to receive the Republican nomination, former president Theodore Roosevelt created the Progressive Party and was chosen as its presidential nominee. The split in the Republican vote made it possible for Democratic Party nominee Woodrow Wilson to win a number of states that had been reliably Republican. Incumbent and Republican nominee William H. Taft (popular vote: 24\%) and Roosevelt $(27 \%)$ lost the election to Wilson (42\%). Although an absolute majority of voters preferred any of the two other major candidates, the Republican split allowed Wilson to secure $82 \%$ of the electoral vote. See Myatt (2007) for a discussion of the 1997 UK general elections, Forsythe et al. (1993) for a discussion of the 1970 U.S. Senate election in New York State, and Bouton and Castanheira (2012) for a discussion of the US presidential election of 2000 in Florida. 
preferences, different voting mechanisms can give rise to different sets of viable alternatives. ${ }^{2}$

The main results of the experiment show that the ability to elect the Condorcet winner depends on the voting mechanism and the underlying information structure. With full knowledge about the preference structure in the electorate voting groups mainly implement the Condorcet winner. Without such information, voters under AV and BC still manage to elect the Condorcet winner at high rates, but fail to do so under PV. Multi-vote systems positively impact the electoral process by enlarging the set of viable alternatives. The Condorcet winner is almost never elected under PV if information about others' preferences is not available. Failures to recognize the Condorcet winner as a viable option under PV are associated with a welfare loss in terms of total surplus generated in the voting groups. However, with enough experience, voters are able to solve the coordination problem in the sense that the Condorcet loser is frequently defeated. This holds true irrespective of the voting mechanism employed and information structure considered.

The paper contributes to the existing literature in several ways. It provides strong evidence that the performance of voting mechanisms in DMPs should not only be judged on their ability to defeat Condorcet losers but should also incorporate the extent to which they elect Condorcet winners. This is an important issue that has been ignored in the literature so far. Furthermore, the experiment provides robustness results for previous findings in the literature. Knowledge about other voters' preferences is not necessarily needed to defeat the Condorcet loser in the presence of repeated interaction (Forsythe et al., 1996). This observation conforms to the idea that the electoral process itself provides voters with institutions that allow them to make good decisions despite their low level of informedness (Wittman, 1989; Lau and Redlawsk, 1997; Page and Shapiro, 2010). However, repeated interaction may not promote efficient coordination under PV. The electoral process under multi-votes systems allows voters to make "better" decisions despite their low level of informedness.

On a more general level, the main findings in this paper suggest that different specifications of the underlying information structure should be taken into account when evaluating the performance of voting methods. If we want to improve collective decision making we should think about ways to improve the informational basis of the electorate. Adopting alternative voting mechanisms could be one way. However, proposals for changes in the electoral systems are often met with reluctance. They require a massive effort to mobilize voter masses so that change may be effectuated. So, if actual electoral reforms are hard to implement from a practical point of view, an easy way to improve the informational basis of the electorate that would be met with less resistance is to change the information technology. Instead of using PV for polls in PV based elections, societies could simply adopt AV or BC as polling technologies to better inform the electorate (Potthoff, 2011).

The remainder of this article is structured as follows. Section 2 presents the theoretical background and experimental hypotheses. Section 3 presents the design and the procedures of the experiment. Section 4 contains the experiment's main results at the outcome level and Section 5 discusses the individual voting data. Section 6 finally concludes.

2 A series of large-scale field experiments on alternative voting mechanisms has recently demonstrated that, once voters are allowed to cast multiple votes, they reveal to be interested in alternatives that were ignored in the corresponding official, PV-based elections (Laslier and Van der Straeten, 2008; Alós-Ferrer and Granić, 2010; Baujard and Igersheim, 2010; Alós-Ferrer and Granić, 2012; Baujard et al., 2014). For example, a different winner would have emerged if AV had been used instead of the official first-past-the-post system in the Constituency Vote for the German Federal Elections in 2009 in the district Konstanz (Alós-Ferrer and Granić, 2012). The AV winner, who was approved of by an absolute majority of voters, was only a minor contender in the official election and came in third. The candidate that came in fourth in the first round of the French Presidential election in 2002 was, filtered through the lens of the official "one man, one vote" voting rule, only a minor contender. Again, AV revealed that the support in the electorate for this particular candidate was much larger than suggested by the official results and comparable in magnitude to the approval rate of the official runner-up (Laslier and Van der Straeten, 2008). 
Table 1: Payoff schedule and induced preference profile.

\begin{tabular}{crrrrrrl}
\hline \hline \multicolumn{6}{c}{ Voter } & \multicolumn{7}{c}{ Payoffs in ECU } \\
Type & Number & A & B & C & D & Induced Preferences \\
\hline & & & & & & \\
Type I & 2 & 100 & 40 & 60 & 80 & $A \succ D \succ C \succ B$ \\
Type II & 3 & 40 & 100 & 60 & 80 & $B \succ D \succ C \succ A$ \\
Type III & 2 & 60 & 40 & 100 & 80 & $C \succ D \succ A \succ B$ \\
\hline Total welfare & 440 & 460 & 500 & 560 & \\
\hline \hline
\end{tabular}

\section{Theoretical background and hypotheses}

\subsection{The voting game}

The experiment employs a voting game with four available alternatives (neutrally labeled $A$, $B, C$, and $D$ ) and three different types of voters. The underlying payoff schedule in terms of experimental currency units (ECU) as well as the corresponding induced strict preferences over the set of alternatives are summarized in Table 1. Seven participants form one group in which voting takes place. The group consists of two voters (Type I) with preferences $A \succ$ $D \succ C \succ B$, three voters (Type II) with preferences $B \succ D \succ C \succ A$ and two voters (Type III) with preferences $C \succ D \succ A \succ B$, where $\succ$ denotes the usual strict preference relation. Participants submit their ballots anonymously and independently and the winner of the election is determined according to a pre-specified voting method (AV, BC, or PV).

The dynamic electoral process is modeled through a repeated game with the voting game represented in Table 1 as the stage game. Participants participate in a series of eight elections keeping constant the group composition and induced preferences. This design explicitly allows participants to interact with each other over several rounds allowing them to form expectations and to develop strategies based on their group's common history. The idea that voters develop expectations about future events based on retrospection can be found, among others, in Fiorina (1981) or McKelvey and Ordeshook (1985b). Information about previous elections results like incumbency and the major competitors are readily available to the public. Empirical evidence supports the existence of an electoral history heuristic and that voters, at least to some degree, perceive of the electoral process as one of repeated interaction (Blais and Bodet, 2006; Lago, 2008; Alós-Ferrer and Granić, 2015). ${ }^{3}$ An analogous design was also used in Forsythe et al. (1993, 1996) to study the dynamics of the electoral process. The next section provides a more detailed motivation for this particular design.

Preferences in the electorate are characterized by a minority of three voters strictly preferring alternative $B$ to all other alternatives. However, alternative $B$ is a (strict) Condorcet loser and constitutes the worst possible outcome for an absolute majority of four voters. In order to avoid their worst outcome, the majority of voters has to coordinate their votes. Although never at the top of any individual's preferences, a natural candidate for coordination should be alternative $D$, the unique Condorcet winner. The preference profile was carefully chosen to align many desirable criteria and having them point to a single alternative. $D$ is not only the Condorcet winner, it is also the winning alternative under BC if everybody votes sincerely and maximizes

3 Although the names of running alternatives may change from race to race, the alternatives themselves often have to go through a party-internal nomination process. Party ideology and discipline restrict the political opinions a running alternative can express. At the same time voters who associate themselves with a certain political spectrum (e.g. left or right) also tend to agree on a large set of issues that are not obviously connected. Voters and alternatives (more precisely the parties/ideas they stand for) can be, hence, conceived of as long lived players who participate in elections repeatedly. 
Table 2: Sincere strategies, admissible strategies, sincere voting outcomes and Nash Equilibrium outcomes in admissible strategies.

\begin{tabular}{|c|c|c|c|c|}
\hline $\begin{array}{l}\text { Voter } \\
\text { Type }\end{array}$ & $\begin{array}{c}\text { Sincere } \\
\text { Strategies }\end{array}$ & $\begin{array}{l}\text { Admissible } \\
\text { Strategies }\end{array}$ & $\begin{array}{c}\text { Sincere Voting } \\
\text { Outcomes }\end{array}$ & $\begin{array}{c}\text { Admissible NE } \\
\text { Outcomes }\end{array}$ \\
\hline \multicolumn{5}{|l|}{ AV } \\
\hline $\mathrm{I}$ & $\mathrm{A}, \mathrm{AD}, \mathrm{ACD}, \mathrm{ABCD}$ & $\mathrm{A}, \mathrm{AC}, \mathrm{AD}, \mathrm{ACD}$ & & \\
\hline II & $\mathrm{B}, \mathrm{BD}, \mathrm{BCD}, \mathrm{ABCD}$ & $\mathrm{B}, \mathrm{BC}, \mathrm{BD}, \mathrm{BCD}$ & $\mathrm{B}, \mathrm{D},\{\mathrm{A}, \mathrm{B}, \mathrm{C}, \mathrm{D}\}$ & $\mathrm{A}, \mathrm{C}, \mathrm{D}$ \\
\hline III & $\mathrm{C}, \mathrm{CD}, \mathrm{ACD}, \mathrm{ABCD}$ & $\mathrm{C}, \mathrm{AC}, \mathrm{CD}, \mathrm{ACD}$ & & \\
\hline \multicolumn{5}{|l|}{$\mathrm{BC}$} \\
\hline $\mathrm{I}$ & $\mathrm{ADCB}$ & Axxx, CAxx, DAxx, xxAB & & \\
\hline II & $\mathrm{BDCA}$ & Bxxx, CBxx, DBxx, xxBA & $\mathrm{D}$ & $\mathrm{A}, \mathrm{B}, \mathrm{C}, \mathrm{D}$ \\
\hline III & CDAB & Cxxx, ACxx, DCxx, xxCB & & \\
\hline \multicolumn{5}{|l|}{ PV } \\
\hline $\mathrm{I}$ & A & $\mathrm{A}, \mathrm{C}, \mathrm{D}$ & & \\
\hline II & B & $\mathrm{B}, \mathrm{C}, \mathrm{D}$ & $\mathrm{B}$ & $\mathrm{A}, \mathrm{C}, \mathrm{D}$ \\
\hline III & $\mathrm{C}$ & $\mathrm{A}, \mathrm{C}, \mathrm{D}$ & & \\
\hline
\end{tabular}

Note: AV: Listed are the approved alternatives. BC: Order of the alternatives corresponds to assigned points of $3,2,1$, and 0 , e.g., Axxx corresponds to the six strategies where $A$ receives 3 points. It is assumed that all voters use the same type of sincere strategy under $\mathrm{AV}$, e.g. approve of top alternative or approve of top two alternatives. Ties are represented by sets of alternatives. There is more than one supporting profile sustaining each admissible NE outcome.

total welfare, where welfare is measured as the total surplus of ECU generated in the election. As shown in the last row in Table 1, voting groups reach a welfare level of 560, 500, 460, and 440 ECUs if $D, C, B$ and $A$ win, respectively. Successful coordination on $D$, hence, maximizes total group payoffs and implementations of $A$ lead to the least efficient outcome for the group.

Table 2 presents a summary of the game-theoretic analysis. A more detailed account thereof is presented in Section 1.2 of the supplementary online materials. The first column in Table 2 identifies the voting method and voter type. The second column shows the sincere strategies, that is, strategies aligned with one's preferences. The third column shows the admissible strategies, that is, the weakly undominated strategies. The fourth and fifth column show the sincere voting outcomes and the Nash equilibirium outcomes in admissible strategies, respectively. The last column shows that there exists a plethora of Nash equilibria even after applying an equilibrium refinement like elimination of weakly dominated strategies. Each of the four alternatives can be sustained as the outcome of at least one Nash equilibrium strategy profile under BC. The same is true for alternatives $A, C$, and $D$ under AV and PV.

While the analysis of Nash equilibrium outcomes in admissible strategies is inconclusive in terms of what outcome one would expect to observe in the experiment, Table 2 also categorizes individual behavior. Sincere voting, except for 'approve of all' under AV, is an admissible strategy under all three voting methods. The only ballot that is weakly dominated under PV is voting for one's least preferred alternative. So are approving of one's least preferred alternative and not approving one's most preferred alternative under AV, and assigning more points to the least preferred alternative than to the most preferred alternative under BC. There are no further (iteratively) dominated strategies.

The categorization highlights how different assumptions about voters' behavior translate into final outcomes. Sincere voting implements the Condorcet loser under PV. If voters strive to implement the Condorcet winner, they have to rely on strategic voting and abandon their most preferred alternative (see Feddersen, 2008, for a definition of strategic voting). Strategic 
voting, thus, helps voters to reach higher welfare levels under PV. Under BC, sincere voting already implements the Condorcet winner and voting groups reach the highest possible welfare level. Strategic voting weakly reduces welfare levels and can only be hurtful in terms of total welfare. Sincere voting does not have unique meaning under AV. As long as there are no 'holes' in the ballot, votes are considered sincere (Brams and Fishburn, 1978). Whether strategic voting helps voters reach higher welfare levels depends on the number of approvals cast under sincere voting. Strategic voting is helpful if either everybody only approves of their most-preferred alternative, in this case the same situation as under PV obtains, or if everybody approves of all alternatives, in this case a tie among the four alternatives obtains. If voters approve of their top-two alternatives or top-three alternatives, AV implements the Condorcet winner and strategic voting is hurtful in this case.

\subsection{Motivation and main research question}

The existing literature on DMPs has contributed to our understanding of how different voting and coordination mechanisms impact the majority's ability to defeat Condorcet losers. It is well understood that alternative voting mechanisms effectively reduce the probability of electing Condorcet losers (Forsythe et al., 1996; Gerber et al., 1998; Morton and Rietz, 2007; Bouton and Castanheira, 2012; Bouton et al., 2016), but PV performs equally well when coordination devices like polls, campaign spending, or shared election histories are available (Forsythe et al., 1993, 1996; Rietz et al., 1998; Andonie and Kuzmics, 2012). Previous work, however, has typically overlooked the important issue of whether voting methods beyond defeating the Condorcet loser also implement the best alternative. The aim of this paper is to bridge this gap by introducing two novelties to the basic set-up studied in this research area.

First, I introduce a novel preference profile. Prior research has focused on a simple model of electoral competition with one minority-backed Condorcet loser and two a-priori equally appealing Condorcet winners. In this set-up defeating the Condorcet loser automatically implements the objectively best alternative. Hence, the issue of whether the best among several alternatives is elected cannot emerge. To overcome this the preference profile that I introduce exhibits a unique, socially, and normatively desirable alternative. As described in Table 1, this role is assumed by the unique Condorcet winner, alternative $D$. How often voting methods implement the Condorcet winner will serve as a measure to evaluate the merits of voting methods.

Second, I introduce uninformed voters in the context of DMPs. It is often assumed in the literature that, rather unrealistically, preferences are publicly known, i.e. that everybody knows the preferences of everybody else. Uncertainty with regard to the relative standing of alternatives among the electorate are assumed away. Abundant evidence suggests that, contrary to this assumption, voters often display a low level of informedness about eligible candidates (Sears and Kinder, 1985). They rely on other sources of information to infer the attractiveness of alternatives (Wittman, 1989; Lau and Redlawsk, 1997; Sinclair and Plott, 2012). This paper introduces uninformed voters as having no a-priori information about the preferences of other voters. They discover or fail to discover viable alternatives through the dynamics of the electoral process itself. ${ }^{4}$ A departure from publicly known preferences to a more realistic information setting can enrich our understanding of why PV is especially prone to DMPs. Without proper

4 The importance of information on voting decisions and how information affects voters' ability to uncover or implement desired outcomes has been studied in a variety of settings. Examples include, among others, the study of two-candidates elections where voters have poor information about the candidate locations (McKelvey and Ordeshook, 1985a,b), studies on the swing voter's curse in the context of the Condorcet Jury model with informed and uninformed committee members (Battaglini et al., 2008, 2010; Morton and Tyran, 2010), and the literature on agenda setting where voters have incomplete information about the agenda setter's most-preferred proposal (Lupia, 1994). 
information regarding the preference profile in the electorate, voters might not recognize that they actually face a DMP or might not be able to identify viable alternatives to coordinate upon.

The latter point connects the two novelties introduced above. Electing the best alternative is tightly intertwined with uncovering the best alternative as a viable option in light of information imperfections. As noted by Cox (1997, p. 7), "Contributors do not contribute, activists do not volunteer for, and citizens do not vote for hopeless candidates, ensuring that those expected to do poorly, do poorly in fact." This observation is conforming to Duverger's (1954) claims that electoral systems have systematic effects on the structure and dynamics of electoral competition. Alternatives expected to perform well under a given voting mechanism will attract the attention of the media, will gather funds for their campaigns, and will perform well in polls. Voting mechanisms can, hence, filter the set of viable alternatives and socially desirable alternatives like the Condorcet winner in Table 1 might go unnoticed to the public. In light of the considerations presented above the two main research questions that the paper investigates are: To which extent do voting methods elect the Condorcet winner and defeat the Condorcet loser? How are these results affected by changes in the information structure?

The multi-vote methods AV and BC studied next to PV in this paper possess the potential to positively impact the electoral process. They offer voters additional opportunities to express their opinions and can enlarge the set of viable alternatives even when preferences are not publicly known. AV, first analytically described in Brams and Fishburn (1978), merely requires voters to reveal which alternatives they find 'acceptable'. Each voter only needs to mark the names of the alternatives he approves of. Arguments distilled from the literature in favor of AV are that the method provides an accurate reflection of voters' wishes and is not vulnerable to voter manipulation (see Brams and Fishburn, 1978; Fishburn, 1978a,b; Myerson, 2002; Brams and Fishburn, 2005; Wolitzky, 2009). Instead of collecting binary information regarding each alternative, BC requires voters to provide a complete ranking (see de Borda, 1781; Saari, 1994). $\mathrm{BC}$ minimizes the amount of paradoxes within the set of positional voting methods (including PV) and the alternative winning BC elections when voters act sincerely is the alternative ranked highest on average in the electorate (see Saari, 1994). ${ }^{5}$

\subsection{Hypotheses}

In light of the experimental design, discussed in more details in the next section, the main research questions can be reformulated in the following way: To which extent do AV, BC, and $\mathrm{PV}$ elect the Condorcet winner $D$ and the defeat Condorcet loser $B$ when common election histories are the only available channel of information? How are these results affected by introducing publicly known preferences? To derive my hypotheses it is assumed that voters' strategic considerations concern the set of viable alternatives. ${ }^{6}$ Only viable alternatives can be expected to amass votes in the dynamic electoral process to compete for winning elections. By design, the experiment isolates the information channels that determine the viability of alternatives. With no information about other voters' preferences, common election histories are the only available information basis for voters to act upon. Alternatives that did not gather

\footnotetext{
5 If we want to understand the implications of alternative voting methods for society, it is essential to collect empirical data on their performance. Field experiments are an important tool in this direction. Unfortunately, the lack of control over participants' preferences makes it impossible to study properties of voting methods outside of the political context in which field experiments are conducted.

6 Previous work has demonstrated that the viability of alternatives organizes voter decisions quite well, both outside and inside the laboratory (Cox, 1997; Alvarez and Nagler, 2000; Van der Straeten et al., 2010; Blais et al., 2011). Viability does not imply that voters actually maximize expected utility based on pivot probabilities as in voting theories based on rational choice theory (e.g. Myerson and Weber, 1993). Voters can also follow simple heuristics. The top-two heuristic describes in Van der Straeten et al. (2010) is one example. Under the top-two heuristic voters form a believe about the two most promising alternatives in terms of chances of winning and simply vote for the alternative they prefer.
} 
votes in the past will not attract any votes in current and future elections. Publicly known preferences introduce a second channel of information on top of this and voters can derive expectations about the viability of alternatives on the basis of the preference profile.

What are the most likely consequences of no information regarding other voters' preferences under the preference configuration from Table 1 and a dynamic electoral process mimicked by a repeated game setting? In the absence of common histories, like in the first election of the electoral process, voters can be presumed to vote sincerely (see, e.g., Merrill and Nagel, 1987). Under PV, sincere behavior implements the Condorcet loser $B$ and there is no recorded ballot in favor of the Condorcet winner $D$ (see Table 2, column Sincere Strategies). The dynamic electoral process under PV does not uncover $D$ as a viable option and $D$ is not expected to win elections. In contrast, sincere voting includes casting votes for $D$ under both AV and BC. Field experiments studying AV show that a large majority of participants cast multiple approvals (see e.g. Alós-Ferrer and Granić, 2012) and one can thus expect a significant number of voters to approve of $D$ in the first election. If voters vote sincerely under $\mathrm{BC}, D$ is implemented right away and $B$ finishes third. Even if participants do not recognize that they actually face a DMP, the votes recorded in favor of $D$ under both AV and BC should transmit the social attractiveness of $D$. Alternative $D$ is expected to be a viable option under both $\mathrm{AV}$ and $\mathrm{BC}$ and voters should frequently implement $D$.

H1. When information regarding other voters' preferences is not available the winning frequency of the Condorcet winner is larger under $A V$ and $B C$ than under $P V$.

Before I turn to the discussion of the publicly known preference case, it is worth noting that there is no clear a priori hypothesis in the comparison between $\mathrm{AV}$ and $\mathrm{BC}$ when voters have no information. The exact extent to which $D$ is implemented and $B$ defeated under AV crucially depends on the amount of voters casting multiple approvals in early elections. If a large enough fraction of voters approves of $D, \mathrm{AV}$ and $\mathrm{BC}$ are outcome equivalent.

What are the most liekly consequences of introducing publicly known preferences? Previous research on DMPs with publicly known preferences shows that coordination devices like polls or election histories under PV and multi-vote systems like AV and BC allow voters to frequently defeat the Condorcet loser (e.g. Forsythe et al., 1993, 1996). In comparison to this stream of literature, introducing $D$ as a fourth option should further increase the salience of coordination among the majority. While coordination on $A$ or $C$ induces asymmetric payoff consequences between the two majority blocks, coordination on $D$ is a natural focal point as every voter is equally well off. $D$ is also a consensus alternative and an acceptable outcome for the minority. Social preferences, equity, and efficiency concerns, thus, increase the attractiveness of $D$ even further. Minority voters might also be willing to vote for $D$ in order to avoid worse alternatives like $A$ or $C$. With publicly known preferences voters should, hence, frequently implement $D$ irrespective of the voting method considered.

H2a. With publicly known preferences the Condorcet winner is frequently implemented irrespective of the voting mechanism used.

The arguments presented above to derive $\mathbf{H 1}$ and $\mathbf{H 2 a}$ imply that the underlying information structure should impact the ability of voting groups to implement $D$ under PV. $D$ is not expected to win elections when information is not available for this method, but is expected to be frequently implemented with publicly known information. The winning frequency of $D$ should, hence, be higher for the latter information structure than for the former one.

H2b. Introducing publicly known preferences increases the winning frequency of the Condorcet winner under $P V$.

The final hypothesis below concerns the dynamics expected to be observed for the winning frequency of $B$. Previous research with publicly known preferences documents frequent failures 
to defeat $B$ under PV in early elections with sharply declining winning frequencies for $B$ over time. The intuition behind this result is straightforward. Defeating $B$ requires successful coordination among several voters. This is difficult to achieve in early elections since voters can only cast single votes under PV. The frequent implementation of $B$ in early elections creates a strong incentive for majority voters to coordinate against the minority. Majority voters can use common election histories as a coordination device to defeat $B$. This basic logic applies to both information structures studied here and the winning frequency of $B$ should therefore sharply decrease as time evolves under PV. Since $B$ is expected to be frequently defeated in early elections under both AV and BC for both information structures, the decrease in $B$ 's winning frequency over time should be less steep under both AV and BC than under PV. AV and $\mathrm{BC}$ offer a richer strategy space. Multiple strategies contribute to the defeat of $B$ and it should be easier for voters to achieve the latter in early elections.

H3. The winning frequency of the Condorcet loser decreases over time under PV. The decrease in the winning frequency of the Condorcet loser is steeper under $P V$ than under both $A V$ and $B C$.

\section{Experimental design}

The experimental laboratory elections were run at the Lakelab (University of Konstanz, Germany). The experimental design, based on Forsythe et al. (1993, 1996), followed a 3 between (voting method: AV vs. BC vs. PV) $\times 2$ between (informational structure: full information vs. no information) design. Preferences over alternatives were induced by means of monetary incentives conditioning participants' remuneration on the outcome of the election. All elections involved four available alternatives and any ties between two or more alternatives were broken randomly. In the full information (FI) treatments, preferences were publicly known, i.e. all participants were informed about the preference profile of the electorate, and the complete history of past elections was common knowledge. In the no information (NI) treatments, participants only knew their own preferences and past election outcomes. Under AV, participants could approve of as many alternatives as wished. The total number of approvals determined the ultimate winner. Under BC, each voters assigned 3, 2, 1 , and 0 points to the alternatives. The alternative with the most points was declared winner. Under PV, participants gave their vote to one alternative only, and the winner was determined by the absolute number of votes received. For each election, participants submitted their voting ballots anonymously and independently and the winner of the election was determined according to the pre-specified voting method. Abstention, including the cast of empty ballots, was not allowed. ${ }^{7}$ To economize notation henceforth, we refer to the six different treatments by abbreviating the corresponding voting method and information treatment, e.g. AVNI refers to the Approval Voting, no information treatment.

\subsection{Procedures}

A total of 12 sessions (two per treatment) were run with 28 participants in each session for a total of 336 participants. Upon arrival, participants were seated in computer-equipped and isolated cubicles. In each session, participants were randomly allocated to four different groups of equal size and a random draw determined the voter 'type' for each participant. During each

\footnotetext{
7 Under AV, approving of all alternatives is equivalent to abstention and participants were allowed to cast of such ballots. This creates a potential asymmetry, however, participants rarely used this strategy (only 97 of 2688 ballots, approx. 3.6\%). The majority of such ballots can be either classified as errors (used once or twice and then never again) or had no payoff consequences (very large winning margins in current and previous elections). The influence of this asymmetry on the results should be minimal to non-existent.
} 
round of the experiment, one election was held within each group. At the end of each election participants were informed about the outcome of the election and the money they earned in this round. All payoffs during the experiment were presented in terms of Experimental Currency Units (ECU) and converted at the end of the experiment at a commonly known fixed rate (100 ECU were worth 60 Euro cents). The group composition and the induced preference profiles were held fixed for a series of eight election rounds. After eight election rounds participants were rematched into new groups and a 'new' set of preferences was induced. For this purpose the computer reshuffled the labels of the alternatives and randomly reassigned the 'types' of the voters. Additionally, small perturbations on the payoff scheme were introduced before the start of the experiment and after regrouping participants. ${ }^{8}$ The regrouping procedure preserved the ordinal structure of the preference profile, so that the overall design was unchanged, but every voter faced a qualitatively new situation. The overall procedure allowed us to observe several different groups within one session while, at the same time, minimizing any repeated game effect that could occur across groups. Each participant completed three series of eight elections and 96 election were held in each session (4 voting groups per series $\times 8$ elections per sereis $\times 3$ series). Thus, each treatment comprises 192 elections held in 24 groups with 1344 ballots cast. ${ }^{9}$

Participants were recruited from a student pool, excluding students from related fields with basic knowledge in Game Theory and Social Choice Theory, via the online recruitment system for economic experiments (Greiner, 2004). The experiment was run using the computer software z-Tree (Fischbacher, 2007). Sessions lasted approximately 1h, no show-up fee was paid, and the average remuneration was $€ 10.66$.

\section{Aggregated election results}

For the presentation of the experiment's results the labels of the alternatives match the original preference profile as presented in Table 1 . Alternative $B$ represents the Condorcet loser and alternative $D$ the Condorcet winner.

\subsection{Summary of election results}

Before investigating the main hypotheses, Figure 1 presents the aggregated election results for all six treatments in terms of fraction of elections won by each of the four alternatives. In case of a tie among $k$ alternatives I treated each alternative in the winner-set as having won the $k^{t h}$ fraction of an election. ${ }^{10}$

As shown in Figure 1, electoral contestation mainly takes place on $D$ and $B$. Alternatives $A$ and $C$, except for the PVNI treatment, display low winning frequencies $(\leq 14 \%)$. Alternative $D$ is the strongest alternative, winning the most elections under AV and BC, regardless of the underlying information structure, and as well as in PVFI. The figures range from $54 \%$ in PVFI to $75 \%$ in AVFI. The winning frequency of $D$ breaks down from $54 \%$ in PVFI to marginal $9 \%$ in PVNI. On average, the multi-vote systems are equally effective in implementing $D$ and are more effective than PV. $B$ obtains its highest winning frequencies among all treatments

\footnotetext{
${ }^{8}$ For each entry in the payoff-matrix, the roll of a ten-sided die determined the direction and the amount of the payoff perturbation. For outcomes from 6 to 10, we added 1 to 5 ECU to and for outcomes 5 to 1 , we subtracted 1 to 5 ECU from the corresponding payoffs in Table 1.

9 Due to a computer error, a different preference profile was induced in the second series of the first session of the PVFI treatment and the data from this series is excluded from the analysis. This treatment thus comprises 160 elections in 20 groups with 1120 ballots.

10 Notwithstanding the relatively small group size in the experiment, a vast majority of election outcomes are non-tied. Percentage of non-tied elections in the different treatments: AVFI - 72\%; AVNI - $65 \%$; BCFI 86\%; BCNI - 83\%; PVFI - 74\%; PVNI - $69 \%$.
} 
Figure 1: The fraction of elections won in each of the six treatments.

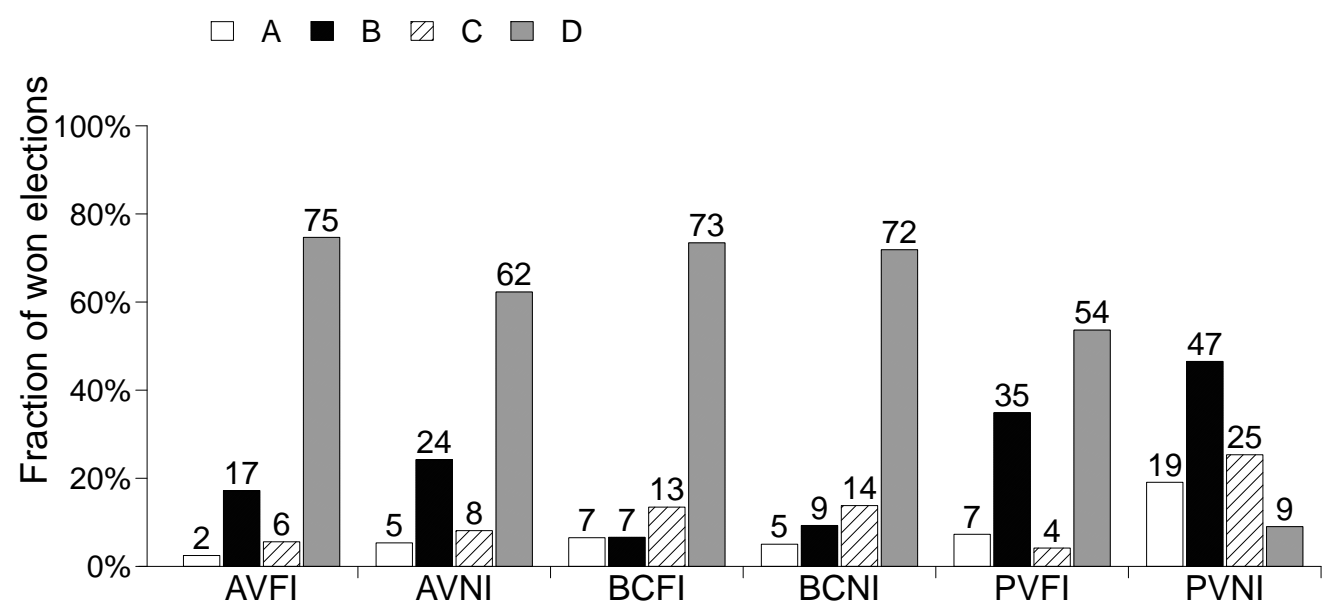

Note: The percentages are rounded and may not add up to $100 \%$. Alternative $D$ is the Condorcet winner, alternative $B$ the Condorcet loser. Number of elections per treatment: 192 (except PVFI: 128).

in PV-based elections with $47 \%$ in PVNI and $35 \%$ in PVFI, respectively. Multi-vote systems, hence, are also on average more effective than PV in defeating $B$. Under BC, $B$ only wins $7 \%$ of the elections under FI and $9 \%$ of the elections under NI, respectively. Under AV, $B$ wins $17 \%$ of the elections under FI and $24 \%$ of the elections under NI, respectively. A more detailed account of the election results is given in Tables 6 to 8 in A and in Section 1.3 of the online supplementary materials.

\subsection{Main hypotheses and results}

Result 1. Confirming hypothesis H1, the winning frequency of the Condorcet winner is larger under both $A V$ and $B C$ than under $P V$ when information about other voters' preferences is not available. This result is robust against learning effects. Voting groups reach higher welfare levels under $A V$ and $B C$ than under $P V$.

To investigate hypotheses $\mathbf{H 1}$, I conduct random-effects panel probit regressions with standard errors clustered at the session level. ${ }^{11}$ The results are shown Table 3 . The dependent variables are indicator variables capturing whether the Condorcet Winner or the Condorcet Loser won the election. The dummy variables for AV and BC in model (1) capture level differences between the two voting methods and PV in electing $D$ for the NI treatments. Both coefficients are significant and positive indicating that voting groups implement $D$ at higher rates under $\mathrm{AV}$ and $\mathrm{BC}$ than under $\mathrm{PV}$. To control for time trends within and across series of elections, model (1) includes a variable for the election period within series (Round) and two dummies for series of elections (Series 2 and Series 3). These variables are interacted with the voting method dummies to account for different time trends across methods. ${ }^{12}$ While the

\footnotetext{
11 As explained in Fréchette (2012), (panel) random-effects estimators minimize the problem of static sessioneffects while clustering at the session level is a robust approach to address interdependence of observations within sessions. I would like to thank an anonymous referee for referring me to this paper. Results from non-parametric tests run on the first series of elections data are in line with the conclusions drawn from the regression analysis. The corresponding test results are reported in Section 1.1 of the supplementary online materials.

12 The presence of interaction terms changes the interpretation of coefficients. For example, the coefficients for Round measures within-series time effects under PV. The interaction term between AV and Round measures whether AV shows a different time trend in the dependent variable than PV. The linear combination of $\mathrm{AV}$, Round, and the interaction between $\mathrm{AV}$ and Round measures the time effect under AV. A discussion on interpreting interaction terms can be found in Brambor et al. (2006).
} 
Table 3: Panel probit estimates with random effects at voting group level.

\begin{tabular}{|c|c|c|c|c|}
\hline \multirow{2}{*}{$\begin{array}{l}\text { Information Structure: } \\
\text { Dependent Variable: }\end{array}$} & \multicolumn{2}{|c|}{ No Information } & \multicolumn{2}{|c|}{ Full Information } \\
\hline & $\begin{array}{l}\text { Condorcet } \\
\text { Winner } \\
(1)\end{array}$ & $\begin{array}{c}\text { Condorcet } \\
\text { Loser } \\
(2)\end{array}$ & $\begin{array}{c}\text { Condorcet } \\
\text { Winner } \\
(3)\end{array}$ & $\begin{array}{l}\text { Condorcet } \\
\text { Loser } \\
(4)\end{array}$ \\
\hline Approval Voting & $\begin{array}{l}3.851^{* * *} \\
(0.628)\end{array}$ & $\begin{array}{l}-1.762^{* * *} \\
(0.266)\end{array}$ & $\begin{array}{l}1.151^{* * *} \\
(0.231)\end{array}$ & $\begin{array}{l}-0.913^{*} \\
(0.419)\end{array}$ \\
\hline Borda Count & $\begin{array}{l}4.119^{* * *} \\
(0.551)\end{array}$ & $\begin{array}{l}-1.849^{* * *} \\
(0.410)\end{array}$ & $\begin{array}{l}0.669^{* * *} \\
(0.179)\end{array}$ & $\begin{array}{l}-1.501^{* * *} \\
(0.304)\end{array}$ \\
\hline Round & $\begin{array}{l}0.309^{* * *} \\
(0.031)\end{array}$ & $\begin{array}{l}-0.262^{* * *} \\
(0.012)\end{array}$ & $\begin{array}{l}0.144^{* *} \\
(0.060)\end{array}$ & $\begin{array}{l}-0.150^{* * *} \\
(0.033)\end{array}$ \\
\hline Series 2 & $\begin{array}{r}0.315 \\
(0.360)\end{array}$ & $\begin{array}{r}0.297 \\
(0.407)\end{array}$ & $\begin{array}{r}0.139 \\
(0.319)\end{array}$ & $\begin{array}{l}0.791^{* * *} \\
(0.090)\end{array}$ \\
\hline Series 3 & $\begin{array}{c}0.246^{*} \\
(0.138)\end{array}$ & $\begin{array}{r}0.128 \\
(0.357)\end{array}$ & $\begin{array}{l}0.741^{* * *} \\
(0.118)\end{array}$ & $\begin{array}{r}-0.081 \\
(0.101)\end{array}$ \\
\hline Round $\times$ Approval Voting & $\begin{array}{l}-0.202^{* * *} \\
(0.040)\end{array}$ & $\begin{array}{l}0.270^{* * *} \\
(0.015)\end{array}$ & $\begin{array}{r}-0.007 \\
(0.118)\end{array}$ & $\begin{array}{l}0.112^{* * *} \\
(0.035)\end{array}$ \\
\hline Round $\times$ Borda Count & $\begin{array}{l}-0.327^{* * *} \\
(0.032)\end{array}$ & $\begin{array}{l}0.198^{* * *} \\
(0.054)\end{array}$ & $\begin{array}{r}-0.080 \\
(0.067)\end{array}$ & $\begin{array}{l}0.139^{* *} \\
(0.058)\end{array}$ \\
\hline Series $2 \times$ Approval Voting & $\begin{array}{c}-0.315 \\
(0.447)\end{array}$ & $\begin{array}{r}-0.012 \\
(0.419)\end{array}$ & $\begin{array}{c}0.585^{*} \\
(0.331)\end{array}$ & $\begin{array}{l}-0.953^{*} \\
(0.542)\end{array}$ \\
\hline Series $3 \times$ Approval Voting & $\begin{array}{r}-0.327 \\
(0.624)\end{array}$ & $\begin{array}{r}-0.086 \\
(0.421)\end{array}$ & $\begin{array}{l}-0.758^{* * *} \\
(0.164)\end{array}$ & $\begin{array}{r}-0.031 \\
(0.430)\end{array}$ \\
\hline Series $2 \times$ Borda Count & $\begin{array}{r}0.038 \\
(0.376)\end{array}$ & $\begin{array}{l}-1.023^{* *} \\
(0.423)\end{array}$ & $\begin{array}{r}0.523 \\
(0.359)\end{array}$ & $\begin{array}{l}-1.353^{* * *} \\
(0.181)\end{array}$ \\
\hline Series $3 \times$ Borda Count & $\begin{array}{r}-0.009 \\
(0.228)\end{array}$ & $\begin{array}{l}-0.842^{* *} \\
(0.359)\end{array}$ & $\begin{array}{r}0.127 \\
(0.365)\end{array}$ & $\begin{array}{l}-0.648^{* *} \\
(0.315)\end{array}$ \\
\hline Constant & $\begin{array}{l}-3.372^{* * *} \\
(0.544)\end{array}$ & $\begin{array}{c}1.402^{* * *} \\
(0.220) \\
\end{array}$ & $\begin{array}{l}-0.349^{* * *} \\
(0.126)\end{array}$ & $\begin{array}{c}0.497^{* * *} \\
(0.138) \\
\end{array}$ \\
\hline Number of Elections & 576 & 576 & 544 & 544 \\
\hline Number of Voting Groups & 72 & 72 & 68 & 68 \\
\hline
\end{tabular}

Note: Dependent variables are dummies. Condorcet Winner (Loser) is 1 if the Condorcet winner (loser) won the election. Independent variables include dummies for the Voting Method and the Series of elections. The variable Round represents the eight elections periods within series. Standard errors are reported in parentheses and are clustered at the session level. Significance is coded as: ${ }^{*} p<0.10,{ }^{* *} p<0.05,{ }^{* * *} p<0.01$.

significant and positive coefficient on Round reveals increasing winning frequencies for $D$ over time under PV, a post-estimation test shows that AV and $\mathrm{BC}$ elect $D$ more often than PV in the very last election round (Wald test: $\chi^{2}(2)=19.38, p<0.001$ ). The learning process observed under PV does not offset AV's and BC's superiority in terms of implementing $D$.

Figure 2 presents $D$ 's and $B$ 's winning frequency over the course of the experiment and illustrates these findings. Elections are labeled consecutively from 1 to 24, vertical lines separate the three series of elections. As shown in the top panel, there exists no election round in which $D$ 's winning frequency under PV is greater than or equal to either of the ones under AV and BC. PV does not uncover $D$ as a viable option and $D$ 's winning frequency is systematically at low levels, albeit increasing over time (38\% considering the last elections of the third series series). AV and BC transmit the strong support of $D$ among the electorate and Voting groups under 
Figure 2: Fractions of elections won by the Condorcet winner and Condorcet loser over the course of the experiment.
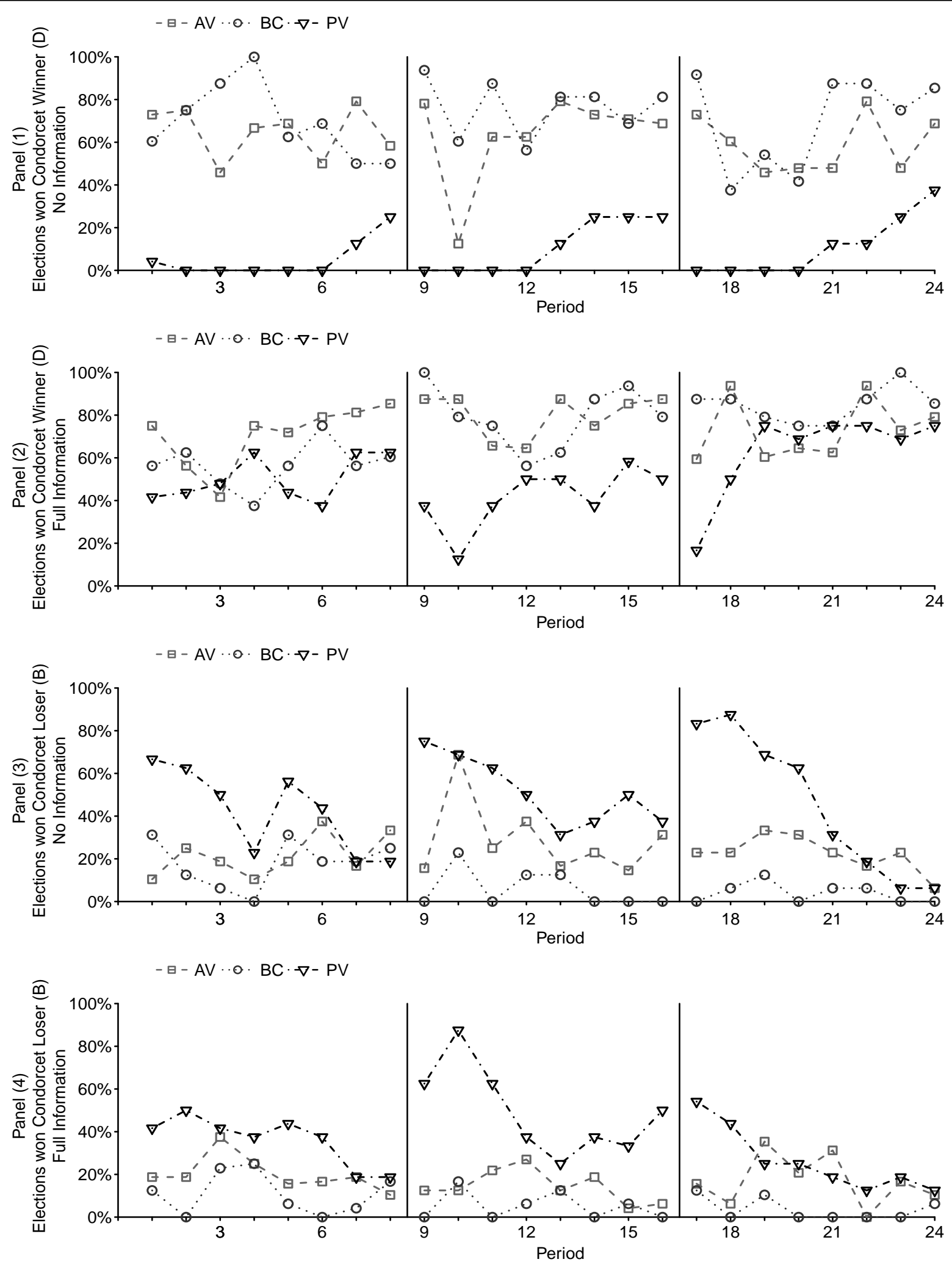

Note: Periods 1 to 8 correspond to the first series, periods 9 to 16 to the second series, and 17 to 24 to the third series of elections. Vertical lines separate the three series of elections.

these two methods are frequently able to implement $D(69 \%$ and $85 \%$, respectively considering the last election within series).

Group welfare levels reflect these findings. I follow the common practice to normalize welfare 
to one for the highest possible welfare level and to zero for the lowest possible level. If $D$ wins an election, a voting group reaches a welfare level of 1 ( 0.5 if $C$ wins, 0.166 if $B$ wins, and 0 if $A$ wins). The higher the rate at which $D$ is implemented the closer the welfare level to 1 . Median per election welfare levels drops from 0.777 under AV and 0.853 under BC to 0.384 under PV (mean $A V=0.728, B C=0.828, P V=0.362$ ). Accounting for learning effects by considering the last election of the third series, Voting groups under $\mathrm{AV}$ and $\mathrm{BC}$ still reach higher per election welfare levels than voting groups under PV (median $A V=B C=1, P V=0.529$; mean $A V=0.816, B C=0.882, P V=0.507)$.

Result 2. Confirming hypothesis H2a, D is the most frequently implemented alternative with publicly known preferences. $D$ wins more elections than $A, B$, and $C$ combined under all three voting methods. After accounting for learning effects no significant differences between methods to elect $D$ are observed and voting groups reach similar welfare levels across methods.

The second panel in Figure 2 shows D's winning frequency for the FI treatments. As hypothesized, knowing the preference profile in combination with common election histories identifies $D$ as a highly viable alternative and $D$ wins a considerable number of elections for all three voting mechanisms. A one-sided Wilcoxon-signed-rank test confirms this observations statistically. For each FI session conducted, the difference in the winning frequencies between alternatives $A, B$, and $C$ combined and alternative $D$ is calculated. Differences smaller than zero indicate that $D$ is the strongest among all alternatives in terms of elections won and that it is systematically implemented. The corresponding null-hypothesis that the median difference is larger or equal to zero is rejected. ${ }^{13}$

The second panel in Figure 2 further reveals differences between methods in the way $D$ 's winning frequency evolves over time. The differences between methods in terms of elections won by $D$ discussed in Section 4.1 are mainly driven by early election rounds. If we consider later rounds of the third series, differences between methods are almost non-existent. In the very last election round alternative $D$ wins $79 \%, 85 \%$, and $75 \%$ of the elections under AV, BC, and PV, respectively. Model (3) in Table 3 confirms these observations statistically. The positive and significant coefficients for $\mathrm{AV}$ and $\mathrm{BC}$ indicate that the two methods implement $D$ at higher rates than PV. As signified by the significant and positive Round coefficient, voting groups learn to implement $D$ over time under PV. This learning process negates differences between methods, a post-estimation test does not reveal any significant differences between methods to elect $D$ (Wald test: $\chi^{2}(2)=0.26, p=0.880$ ). These patterns are also reflected in the analysis of welfare. The median welfare level reached per voting group per election is 0.876, 0.864, and 0.660 under $\mathrm{AV}, \mathrm{BC}$, and PV, respectively (mean $A V=0.837, B C=0.834$, $P V=0.625)$. Voting groups reach higher welfare levels under $\mathrm{AV}$ and $\mathrm{BC}$ than under $\mathrm{PV}$. However, these differences disappear if data is restricted to the last election in the third series (median $A V=B C=P V=1$; mean $A V=0.864, B C=0.888, P V=0.761$ ).

Result 3. Confirming H2b, the winning frequency of $D$ under $P V$ is larger with publicly know preferences than when preferences are not known. After accounting for learning effects voting groups under $P V$ defeat $B$ at the same rate under both information treatments. Notwithstanding, voting groups reach higher welfare levels with publicly known preferences under PV.

To investigate hypothesis $\mathbf{H 2} \mathbf{b}$, Table 4 presents the results of random-effects panel probit estimates with standard errors clustered at the session level. The data is restricted to PV and the regressions include a dummy for the No Information treatment. The dependent variables and remaining independent variables follow the same interpretation as in Table 3 . The No Information dummy captures level differences between information treatments under PV in electing $D$ and defeating $B$. The significant and negative coefficient in model (1) indicates that

\footnotetext{
$13 N=6, Z=-1.9, p=0.031$. Difference in winning frequencies between $(A, B, C)$ and $D:$ median $=$ -0.395 , mean $=-0.339$.
} 
Table 4: Panel probit estimates with random effects at voting group level, across information treatments.

\begin{tabular}{|c|c|c|}
\hline \multirow{2}{*}{$\begin{array}{l}\text { Information Structure: } \\
\text { Dependent Variable: }\end{array}$} & \multicolumn{2}{|c|}{ Plurality Voting } \\
\hline & $\begin{array}{l}\text { Condorcet } \\
\text { Winner } \\
\text { (1) }\end{array}$ & $\begin{array}{l}\text { Condorcet } \\
\text { Loser } \\
(2)\end{array}$ \\
\hline No Information & $\begin{array}{l}-3.838^{* * *} \\
(0.674)\end{array}$ & $\begin{array}{l}0.998^{* * *} \\
(0.297)\end{array}$ \\
\hline Round & $\begin{array}{l}0.165^{* * *} \\
(0.056)\end{array}$ & $\begin{array}{l}-0.148^{* * *} \\
(0.039)\end{array}$ \\
\hline Series 2 & $\begin{array}{r}0.236 \\
(0.301)\end{array}$ & $\begin{array}{l}0.781^{* * *} \\
(0.045)\end{array}$ \\
\hline Series 3 & $\begin{array}{l}0.822^{* * *} \\
(0.029)\end{array}$ & $\begin{array}{r}-0.078 \\
(0.357)\end{array}$ \\
\hline Round $\times$ No Information & $\begin{array}{l}0.214^{* *} \\
(0.093)\end{array}$ & $\begin{array}{l}-0.133^{* * *} \\
(0.039)\end{array}$ \\
\hline Series $2 \times$ No Information & $\begin{array}{r}-0.028 \\
(0.631)\end{array}$ & $\begin{array}{r}-0.441 \\
(0.436)\end{array}$ \\
\hline Series $3 \times$ No Information & $\begin{array}{r}-0.599 \\
(0.142)\end{array}$ & $\begin{array}{r}0.222 \\
(0.403)\end{array}$ \\
\hline Constant & $\begin{array}{l}-0.574^{* * *} \\
(0.028)\end{array}$ & $\begin{array}{l}0.488^{* * *} \\
(0.179)\end{array}$ \\
\hline Number of Elections & 352 & 352 \\
\hline Number of Voting Groups & 44 & 44 \\
\hline
\end{tabular}

Note: Dependent variables are dummies. Condorcet Winner (Loser) is 1 if the Condorcet winner (loser) won the election. Independent variables include dummies for the no Information treatment and the Series of elections. The variable Round represents the eight elections periods within series. Standard errors are reported in parentheses and are clustered at the session level. Significance is coded as: ${ }^{*} p<0.10,{ }^{* *} p<0.05,{ }^{* * *}$ $p<0.01$.

having no information regarding other voters' preferences, as expected, reduces the rate with which $D$ is implemented. A post-estimation test reveals that this difference is significant for the last election round (Wald test: $\chi^{2}(1)=16.63, p<0.001$ ) and, hence, robust against learning effects. A different picture emerges for the winning frequencies of $B$. The significant and positive coefficient of No Information in model (2) indicates that voting groups defeat $B$ more often when preferences are publicly known. However, considering the last election in the third series, there is no significant difference across information treatments under PV in defeating $B$ (Wald test: $\chi^{2}(1)=0.18, p=0.668$ ). Figure 2 illustrates these findings. Comparing the top and second panel we observe that voting groups implement $D$ at higher rates in PVFI than PVNI throughout the experiment. Comparing the third and fourth panel, we observe that failures to defeat $B$ are higher in PVNI than in PVFI in early election rounds only. The low level at which $D$ is implemented under PVNI is costly for the society as a whole and voting groups reach higher welfare levels in PVFI. Considering the last election in the third series, the median welfare level reached is 1 in PVFI (mean $=0.761)$, and 0.529 in PVNI (mean $=0.507)$.

Result 4. Confirming hypothesis H3, the winning frequency of the Condorcet loser decreases over time under $P V$ and this decrease is sharper than the ones under $A V$ and BC. After accounting for learning effects, the three voting methods defeat $B$ at comparable rates. 
The regression results presented in model (2) and (4) in Table 3 investigate the ability of voting groups to defeat $B$. The significant and negative Round coefficients in both models indicate that, as expected, $B$ 's winning frequency is declining over time under PV. Independent of the underlying information structure, voting groups learn to defeat $B$. The significant and positive coefficients on the interaction terms between Voting Method and Round confirm the second part of hypothesis H3. The decrease in $B$ 's winning frequency is less negative under $\mathrm{AV}$ and $\mathrm{BC}$ than under PV. Accounting for learning effects by considering the last elections of the third series, post-estimation test detect weakly significant differences among methods in defeating $B$ for the FI treatments (Wald test: $\chi^{2}(2)=4.86, p=0.088$ ) and significant differences between methods for the NI treatments (Wald test: $\chi^{2}(2)=166, p<0.001$ ). These differences are mainly driven by the low rate at which voting groups implement $B$ under $\mathrm{BC}$, the differences between AV and PV are not significant.

These observation are illustrated in the third and fourth panel in Figure 2. B's median winning frequency over voting groups under PV is highest in the first two elections within series (58\% and $88 \%$ for FI and NI, respectively) and drops to low levels in the last two elections within series ( $0 \%$ for both FI and NI). As theorized in Section 2.3, voting groups defeat $B$ at higher rates in early elections under the multi-vote systems AV and BC, however the learning process under PV reduces differences across methods in later elections (median winning frequency early vs late rounds AVFI: $0 \%$ vs $0 \%$, AVNI: $25 \%$ vs $16 \%$, BCFI: $0 \%$ vs $0 \%$, BCNI: $0 \%$ vs $0 \%$ ). The pronounced difference in terms of defeating $B$ discussed in Section 4.1 are mainly driven by early election rounds. Accounting for learning eliminates the discrepancy between methods and all three voting methods defeat $B$ at comparable rates.

\subsection{Summary of the main findings}

The high rate at which voting groups implement $D$ when preferences are publicly know validates the general approach taken in this paper. As theorized, $D$ is a highly salient and a highly desirable alternative. When all relevant information is available to the public voting groups voluntarily and readily implement it. However, the latter result crucially depends on the underlying information structure. In the absence of information about other voters' preferences the electoral process under PV does not uncover $D$ as a viable option. The desirability and strong support in the electorate of $D$ is only poorly transmitted under this voting method. This inefficiency is costly for the society as a whole. The shift in electoral competition away from $D$ towards alternatives $A$ and $C$ observed in PVNI mainly comes at the expenses of the Type II minority voters (mean per election payoff PVFI vs PVNI for - Type I: 64.7 vs 62.2; - Type II: 82.6 vs 75.0 ; - Type III: 64.4 vs 64.7 ). The minority would be better off with full information.

In contrast, multi-vote systems dissolve information imperfections effectively and election results are relatively robust and stable under both information treatments in the experiment. $\mathrm{AV}$ and $\mathrm{BC}$ elect $D$ more often and clearly outperform PV when information about other voters' preferences is not present. The experiment highlights the importance of publicly known preferences for coordination devices to alleviate coordination problems in DMPs. The results demonstrate that repeated interaction as a coordination device can promote the ability to defeat $B$ but might fail to do so efficiently in DMPs with no information about other voters preferences under PV. Finally, the results suggest that, in general, different specifications of the underlying information structure and the responsiveness of voting methods towards changes thereof should be taken into account when evaluating the merits of voting methods. 


\section{Individual voting behavior}

This section discusses the individual voting behavior underlying the aggregate election results. All three voting methods have in common that voters seldom use dominated ballots. The classification as dominated ballot originates from the analysis of the one-shot game as presented in Table 2. Pooled over information treatments, dominated ballots account for $1.7 \%, 3.6 \%$, and $10.4 \%$ of observed ballots under PV, BC, and AV, respectively. In case of AV, $8.6 \%$ of the dominated ballots approve of $D$ and $4.1 \%$ approve of $D$ only. In general, the vast majority of dominated ballots in the experiment are cast in situations with high winning margins in current and/or in previous election rounds. They can be rationalized in the sense that a change in the behavior from dominated to admissible ballot would not have affected the outcome of the election. The individual data on dominated ballots suggests that participants understood the preference profile studied here and the consequences of their action for the different methods. A more detailed account on ballots cast in the experiment is given in Table 9 in A.

\subsection{Approval Voting}

AV has been shown to provide few incentives to cast non-sincere ballots under many different circumstances both theoretically and empirically (see, e.g., Forsythe et al., 1996; Wolitzky, 2009; Dellis et al., 2011) and the experiment's results confirm these findings. The most frequent ballots observed in the experiment are the sincere ones (87.3\% in AVFI and $96.1 \%$ in AVNI). However, different voter types display heterogeneity in the distribution of ballots. Under FI (NI), Type I and Type III voters, with relative frequencies of $45.3 \%(51.3 \%)$ and $52.1 \%(54.2 \%)$ respectively, approve of their two most preferred alternatives more often than Type II voters, who do so with a relative frequency of $32.6 \%$ (28.6\%). The player types also differ in their propensities to approve of only their most preferred alternative. Type II voters approve of only $B$ in $49.5 \%(58.2 \%)$ of elections, in comparison to $19.3 \%(37.8 \%)$ of Type I voters approving only of $A$ and $25.3 \%$ (28.4\%) of Type III voters approving only of $C$. These patterns clearly reflect the different strategic considerations induced by the different player roles. $B$ and $D$ are among the winning alternatives in 135 and 322 out of 384 elections and finish as runner-up in further 193 and 40 elections, respectively. They constitute the two most viable alternatives. Majority voters try to implement $D$ to defeat $B$ and double vote often while minority voters try to implement $B$ and often approve of $B$ only. However, if $A$ or $C$ contest against $D$ for the first place, majority voters start to abandon $D$ and tend to approve of their most preferred alternative only . Likewise, minority voters increase their support of $D$ and tend to approve of $B$ and $D . D$ is thus frequently implemented under AV as the result of two different motives to support it. On the one hand, $B$ is viable under AV and majority voters approve of $D$ to defeat $B$. On the other hand, minority voters approve of $D$ to avoid worse alternatives. The observed heterogeneity in the use of sincere ballots within and across voter types suggests that AV does not eliminate strategic considerations. Due to the multiplicity of sincere ballots, AV shifts the level of strategic consideration from 'Which ballot should I cast?' to 'Which sincere ballot should I cast' (see Niemi, 1984; Nagel, 2007).

\subsection{Plurality Voting}

Individual voting behavior under PV can also be structured along the viability of alternatives. While the share of won elections by $B$ decreases over time, $B$ is often the major contender for the first place and finishes as runner-up in 231 out of 352 elections. The minority block voters almost always vote for the viable alternative $B(85.2 \%$ under FI and $87.7 \%$ under NI) and there is only little variation in these figures over time. To defeat $B$, the majority block voters have to coordinate on one alternative. The process to uncover the most viable option takes time 
and results in large winning frequencies of $B$ in the first elections. This is evidenced by the high level of sincerity among majority voters in the first two elections withing series (PVFI: 43.8\%, PVNI: 88.5\%). For example, Alternative $C$ in PVFI is among the winner alternatives or finishes as runner-up in roughly half of the elections in the first two periods within series. This figure drops to $10 \%$ in the last two periods within series. As time progresses, the majority block voters decrease their level of sincerity (last two elections within series PVFI: 16.3\%, PVNI: $59.9 \%$ ). The winning frequencies of $B$ decrease as the majority succeeds to coordinate on one alternative. Which alternative the majority coordinates on crucially depends on the information treatment. With full information the majority mainly coordinates on $D$. Type I and Type III voters abandon their most preferred alternative and vote for $D$ in $66.6 \%$ and $54.7 \%$ of all elections, respectively. With no information the majority block voters try to coordinate on either $A$ or $C$. They decrease their number of votes cast in favor of $D$ to $10.7 \%$ and $10.4 \%$, respectively, in the NI treatment. At the same time, they increase their number of votes cast in favor of their third most preferred alternatives (from $4.1 \%$ in FI to $24.2 \%$ in NI for Type I voters and from $11.3 \%$ to $18.2 \%$ for Type II voters, respectively). As hypothesized in Section 2.3, sincere behavior is largest in the first election within series under NI (Type I: 93.8\%, Type II: $83.3 \%$, Type III: $87.5 \%$ ) and declines over time. In summary, the PV data suggests that the minority is motivated to implement $B$ and often votes sincerely. The majority tries to defeat $B$ and concentrates their votes on the most viable alternative. ${ }^{14}$

\subsection{Borda Count}

Concerning the $\mathrm{BC}$ elections, the sincere ballot was the ballot cast most frequently under both information treatments (BCFI: 42.0\%, BCNI: 46.5\%). However, this high level of sincerity should not be equated with an absence of strategic considerations. Only a minority of 6 out of 112 participants in the $\mathrm{BC}$ treatments cast the sincere ballot more than 20 times in the 24 elections they participate in. Participants frequently change the ballots they cast on a period to period basis and the median number of switches per participant equals 10 (out of 21 possible switches). Further, the second largest and third largest ballot categories capture active misrepresentation of preferences on part of the voters. The first of these two categories captures ballots allotting 3 points to the most preferred alternative and more than zero points to the least preferred one. This strategy is known as 'burying' competing alternatives (BCFI: 21.8\%, BCNI: $23.9 \%$, see category TopWorst $>0$ in Table 9). The second category represents admissible ballots assigning 2 points to the most preferred alternative. This strategy is known as 'compromising' (BCFI: 25.1\%, BCNI: $18.7 \%$, see category Second in Table 9). The majority of 'burying' ballots assign zero points to $D(57 \%)$ and are cast in situations in which $D$ and the most preferred alternative of the corresponding voter type contest for the win. The vast majority of 'compromising' ballots assign 3 points to $D(97 \%)$ and are cast in situations that see undesirable alternatives contest for the win. These two categories indicate the high amount of participants insincerely decreasing alternatives and insincerely increasing alternatives in their ranking in order to change the outcome of the election to their favor. In fact, a total of 60 participants cast both burying ballots assigning zero points to $D$ and compromising ballots assigning three points to $D$ depending on the electoral history. The strong strategic motive present for all three voter types supports criticism expressed against BC as being easy to manipulate (Brams et al., 1988). The results here suggest that it is relatively easy for voters

\footnotetext{
14 Under both $\mathrm{AV}$ and $\mathrm{PV}$, the minority tends to adopt voting strategies that favor $B$. However, there is a substantial number of minority voters who double vote under AV supporting the $B$ as well as $D$. At the same time minority voters under PV have a lower propensity to give up their first choice and vote for $D$. This 'inclusive' feature of AV and 'exclusive feature' of PV has also been observed both in the laboratory in the context of parochailism (Baron et al., 2005) as well as in a large scale field experiment conducted in parallel to the 2012 French presidential election (Baujard et al., 2014).
} 
to understand burying and compromising as means to manipulate the outcome to their favor. Given the high winning frequencies of $D$ under BC, these simple heuristics cancel each other out in the aggregate. As in the case of $\mathrm{AV}$ and $\mathrm{PV}$, the different types of voters display heterogeneity in the distribution of ballots. However, the level of heterogeneity is by far not as pronounced as under AV and differences between the two information treatments are rather small. The latter observation supports the findings in Kube and Puppe (2009) who show that the amount of available information has only little influence on the frequency of mis-aligned voting under BC.

\subsection{The importance of strategic considerations}

The aim of this section is to demonstrate that strategic considerations were an important part of the decision making process. To achieve this I analyze two channels of strategic considerations. The first channel represents the strategic response in understanding the consequences of one's actions for a given voting method and the respective link to the voter type (i.e., payoff consequences). Given that participants were randomly assigned to the treatments and voter types, systematic differences in the behavior between voter types for a given voting method measure the adaptiveness of participants to the environment set by the voting method and the underlying information structure. The second channel investigated here are the strategic responses of voters to available information in form of election histories. Participants can use this information and react to the actions taken by the other voters in the past, for example using myopic best-reply dynamics or simpler heuristics (Erev and Roth, 1998) or retrospective voting (Fiorina, 1981). They can also use this information and try to predict the behavior of others and act accordingly like in models of rational choice (Myerson and Weber, 1993; Myerson, 2000). In either way we should observe a strong link between election histories and voting behavior. To investigate the two channels and how they influence individual voting behavior I conduct random-effects panel probit regressions with standard errors clustered at the session level further. The results are reported in Table 5. Before I proceed, I would like to note that the estimated models are by no means meant to be a complete description of individual voting data. They are a parsimonious, crisp way to highlight the main ideas without unnecessarily complicating the exposition.

Each column in Table 5 corresponds to the regression analysis for one of the three voting methods. Ballots cast are treated as independent observations and each voting method data comprises two information treatments. For each voting method we consider a different dependent variable. The choice of these three dependent variables is motivated by the objective to display the effects of the two postulated channels of strategic considerations in the most parsimonious way. At the same time the models should be able to accommodate the two main observations from the previous sub-section. First, the behavioral heterogeneity with respect to the voting situation under AV and PC. Second, the behavioral heterogeneity with respect to election histories present for all three methods. Fixing the same set of regressors, which dependent variables are suitable? For AV and PV, the dependent variable is the dummy Top which takes on the value 1 if voters approve of or vote for their most preferred alternative only. The rationale for using Top is straightforward. The use of Top ballots differs across voter types (see Table 9). In reaction to $B$ winning the past election, i.e. $B$ is highly viable, minority voters should increase and majority voters should decrease the share of Top ballots cast. For $\mathrm{BC}$, the dependent variable is the dummy TopWorst $>0$ which equals 1 if voters assign 3 points to their most preferred alternative and assign more than 0 points to their least preferred alternative under BC. These ballots corresponds to the burying strategy, where voters assign a maximum number of points to their preferred alternative, however insincerely lower the points of a less desirable, probably competing alternative. This type of ballot is particularly suited 
Table 5: Panel probit estimates with random effects at individual level.

\begin{tabular}{lccc}
\hline \hline Voting Method: & AV & BC & PV \\
Dependent Variable: & Top & TopWorst $>0$ & Top \\
\hline Type II & 0.781 & 0.017 & $1.811^{* * *}$ \\
Type III & $(0.485)$ & $(0.079)$ & $(0.506)$ \\
No Information & $0.379^{*}$ & $0.253^{* * *}$ & 0.338 \\
& $(0.214)$ & $(0.047)$ & $(0.228)$ \\
No Information $\times$ Type II & $0.641^{*}$ & -0.120 & $1.340^{* * *}$ \\
& $(0.380)$ & $(0.157)$ & $(0.308)$ \\
No Information $\times$ Type III & -0.392 & $0.389^{* * *}$ & $-1.507^{* * *}$ \\
& $(0.475)$ & $(0.085)$ & $(0.503)$ \\
Condorcet Loser t-1 & -0.342 & 0.112 & -0.116 \\
& $(0.249)$ & $(0.246)$ & $(0.248)$ \\
Condorcet Loser t-1 $\times$ Type II & $-0.546^{* * *}$ & -0.444 & 0.066 \\
& $(0.023)$ & $(0.310)$ & $(0.124)$ \\
Condorcet Loser t-1 $\times$ Type III & $1.213^{* * *}$ & $0.905^{* * *}$ & $1.374^{* * *}$ \\
& $(0.070)$ & $(0.198)$ & $(0.175)$ \\
Constant & $0.340^{* * *}$ & -0.335 & -0.187 \\
\hline Number of Ballots & $(0.099)$ & $(0.382)$ & $(0.198)$ \\
Number of Subjects & $-1.047^{* * *}$ & $-1.056^{* * *}$ & $-0.866^{* * *}$ \\
\hline \hline
\end{tabular}

Note: All dependent variables are dummies. Independent variables include dummies for the no information treatment, Type II and Type III voters, and the Condorcet loser winning the previous election (zero if first round within a series). Standard errors are reported in parentheses and are clustered at the session level. Significance is coded as: ${ }^{*} p<0.10,{ }^{* *} p<0.05,{ }^{* * *} p<0.01$.

to highlight responses to $B$ winning the past election. By casting the TopWorst $>0$ ballot, minority voters assign the maximum number of points to $B$ and assign zero points to either $C$ or $D$, the two most viable alternatives and most probably competing against $B$ for the win in the previous election. By casting the TopWorst $>0$ ballot, majority voters assign strictly more than zero points to $B$. To push $B$ minority voters should adopt and to defeat $B$ majority voters should abandon TopWorst $>0$ ballots. ${ }^{15}$

Notice that each estimation includes the same set of regressors representing two different channels of strategic considerations. The first channel, participants' adaptiveness to the environment, is measured by dummy variables for Type II voters, Type III voters, and for the NI

\footnotetext{
15 As shown in Table 9, the four largest categories of ballots cast in the experiment are the Sincere one, the TopWorst $>0$, the Second, and the TopWorst $=0$ ones. In comparison to the TopWorst $>0$ ballot the Sincere one assigns more points to $D$ or $C$ for the minority and less points to $B$ for the majority. $97 \%$ of the Second ballots assign 3 points to $D$ of which, in turn, $81 \%$ also assign zero points to the least preferred alternative. Thus, in comparison to the TopWorst $>0$ ballot the Second one assigns less points to $B$ and more points to $D$ for the minority and assigns more points to $D$ and to a large extent less points to $B$ for the majority. Finally, the TopWorst $=0$ ballot assigns 3 points to the most preferred, 2 points to the third most preferred, 1 point to the second most preferred, and zero points to the least preferred alternative. In comparison to TopWorst $>0$, TopWorst $=0$, thus, assigns more points to $C$ or $D$ for the minority and less points to $B$ for the majority.
} 
treatment. The regressions also include the interaction of these variables. The second channel, participants' reaction to past elections, is measured in a myopic way through the dummy variable Condorcet loser $t-1$ which takes on the value 1 if the previous election was won by the Condorcet loser.

The results in Table 5 clearly reflect participants' self-interested, strategic responses through the postulated channels and validate the choice of the dependent variables. First, we observe significant differences in the behavior between types. With FI, the significant Type II dummy indicates that Type II voters have larger propensities to use Top actions under PV than Type I voters. Clearly, Type II voters from the minority block try to implement $B$ and, hence, use strategies that increase the probability of their most preferred alternative winning the election to a greater extent than Type I voters. The significant Type III dummies indicate that Type III voters have a higher propensity to cast Top ballots than Type I voters under AV and a higher propensity to cast TopWorst $>0$ ballots than Type I voters under BC. How do we interpret the difference between Type III and Type I voters? Remember that the induced preference profile is asymmetric. Alternative $A$, the most preferred alternative of Type I voters, is the least preferred alternative of the minority block. Alternative $C$, the most preferred alternative of Type III voters, is the second worst option for the minority block. This asymmetry is also reflected in the election results. Consult for example Figure 1. $C$ wins more elections than $A$ and $A$ almost never wins. Supporting actions of Type III voters in favor of $C$ are more fruitful than supporting actions of Type I voters in favor of $A$. The former are more likely to work and hence are used more often by Type III voters.

NI, as indicated by the significant coefficient of the corresponding dummy, increases the probability that Type I voters use Top ballots under AV and PV. Post estimation tests show that this is also the case for Type III voters (AV: $z=2.80, p=0.005$; PV: $z=4.72, p<0.001$ ). Having less available information increases the probability for voters from the majority block to vote sincerely under PV and to use 'approve of the most preferred alternative' ballots under AV. The significant interactions between the NI dummy and the Type II dummy also reveal that the behavioral response to less available information differs across the minority and majority block. Post estimation tests reveal that NI increases the propensity to cast TopWorst $>0$ ballots under BC and has no effect on the propensity to cast Top ballots for Type II voters under PV (BC: $z=2.54, p=0.011 ; \mathrm{PV}: z=-1.37, p=0.171$ ). In general, the behavioral heterogeneity in response to less available information across voter types suggests that NI reduces the scope of misrepresentations of preferences, but does not eliminate strategic considerations altogether.

Finally, election histories have a significant effect on voting behavior. The Condorcet loser winning the previous election significantly increases the probability that the minority voters cast ballots supporting $B$ under all three methods. Type II voters are more likely to approve of $B$ only, to give $B 3$ points and bury a competing alternative, and to vote for $B$ if $B$ won the previous election (AV: $z=8.08, p<0.001$; $\mathrm{BC}: z=2.48, p=0.013$; PV: $z=8.27, p<0.001$ ). Type I and Type III voters show a larger propensity to double or triple vote after seeing $B$ win an election under AV. The latter also use the TopWorst $>0$ ballot less often in that event under $\mathrm{BC}(z=-5.61, p<0.001)$. TopWorst $>0$ translates into giving more than zero points for $B$ for Type III voters. Hence, majority voters actively increase the number of approvals for non- $B$ alternatives under AV and actively decrease the number of points $B$ receives under BC.

In summary, the regression analysis corroborates that the two hypothesized channels of strategic reasoning significantly predict behavior of participants in the direction of self-interested voting decision. This clearly establishes the importance of strategic behavior of the participants. There also exists stark differences between AV, PV, and BC. In contrast to the former two voting methods, the heterogeneity in voting behavior under BC as reactions to the strategic environment are not as pronounced. Van der Straeten et al. (2010), for example, show that rational choice theory provides good predictions of actual behavior for AV and PV elections. 
However, the authors also show that under more complex voting methods, where strategic consideration are cognitively demanding, voters tend to rely on simpler heuristics. BC might be more complex than AV and PV and voters use simpler, heuristic based reactions to past election histories.

\section{Conclusion}

This article has reported on the results of a series of experimental, four-alternative elections in which the induced preference profile in the electorate corresponded to a divided majority problem. The divided majority was given three possibilities to coordinate their votes on. Two alternatives represented the most favored alternative of one of the two divided majority blocks. The third alternative constituted a unique Condorcet winner ranking second in each participant's preference profile. The preference profile aligned many normative criteria having them point to a single alternative. The Condorcet winner would also win the Borda Count election if voters acted sincerely and maximizes the sum of all individual payoffs. In a second step, the experiment manipulated the amount of available information that voters had from a full information framework where each voter was fully informed about the preference structure in the whole electorate to an no information framework where voters only knew their own payoffs and the election histories.

The novelty of the design disentangled the ability to defeat the Condorcet loser from the ability to elect the Condorcet winner, a distinction that has not gained any attention in the existing literature so far. The main results of the experiment showed that multi-vote systems like Approval Voting and Borda Count outperform Plurality Voting in divided majority problems in terms of the ability to elect the Condorcet winner in the absence of information about other voter's preferences. The underlying information structure had a huge impact on election outcomes and individual behavior under Plurality Voting, even for a fixed set of preferences. At the same time, Approval Voting and Borda Count were less responsive to changes in the underlying information structure. However, with enough experience, voters were able to solve the coordination problem across all three methods in the sense that the Condorcet loser was often defeated. The electoral process itself, modeled through a repeated-game structure, provided voters with enough information allowing them to make good decisions despite their low level of informedness. Approval Voting and the Borda Count, by design, give voters the opportunity to send much richer and finer ballot messages. They transmitted enough information through their ballot structures effectively eliminating information imperfections. In this sense, multi-votes systems allowed voters to make "better" decisions despite their low level of informedness.

\section{References}

Alós-Ferrer, C., Granić, Đ.-G., 2010. Approval Voting in Germany: Description of a Field Experiment. In: Laslier, J.-F., Sanver, M. R. (Eds.), Handbook on Approval Voting. Springer.

Alós-Ferrer, C., Granić, Đ.-G., 2012. Two Field Experiments on Approval Voting in Germany. Social Choice and Welfare 39 (1), 171-205.

Alós-Ferrer, C., Granić, Đ.-G., 2015. Political Space Representations with Approval Data. Electoral Studies 39, 56-71.

Alvarez, R. M., Nagler, J., 2000. A New Approach for Modelling Strategic Voting in Multiparty Elections. British Journal of Political Science 30 (1), 57-75. 
Andonie, C., Kuzmics, C., 2012. Pre-election Polls as Strategic Coordination Devices. Journal of Economic Behavior \& Organization 84 (2), 681-700.

Baron, J., Altman, N. Y., Kroll, S., 2005. Approval Voting and Parochialism. Journal of Conflict Resolution 49 (6), 895-907.

Battaglini, M., Morton, R., Palfrey, T., 2008. Information Aggregation and Strategic Abstention in Large Laboratory Elections. American Economic Review 98, 194-200.

Battaglini, M., Morton, R., Palfrey, T., 2010. The Swing Voter's Curse in the Laboratory. Review of Economic Studies 77, 61-89.

Baujard, A., Igersheim, H., 2010. Framed Field Experiments on Approval Voting: Lessons from the 2002 and 2007 French Presidential Elections. In: Laslier, J.-F., Sanver, M. R. (Eds.), Handbook on Approval Voting. Springer.

Baujard, A., Igersheim, H., Lebon, I., Gavrel, F., Laslier, J.-F., 2014. Who's favored by evaluative voting? An experiment conducted during the 2012 French presidential election. Electoral Studies 34, 131-145.

Black, D., 1958. The Theory of Committees and Elections. Camebridge: Camebridge University Press.

Blais, A., Bodet, M. A., 2006. How Do Voters Form Expectations about the Parties' Chances of Winning the Election? Social Science Quarterly 87 (3), 477-493.

Blais, A., Labbé-St-Vincent, S., Laslier, J.-F., Sauger, N., Van der Straeten, K., 2011. Strategic Vote Choice in One-round and Two-round Elections: An Experimental Study. Political Research Quarterly 64 (3), 637-645.

Bouton, L., Castanheira, M., 2012. One Person, Many Votes: Divided Majority and Information Aggregation. Econometrica 80 (1), 43-87.

Bouton, L., Castanheira, M., Llorente-Saguer, A., 2016. Divided majority and information aggregation: Theory and experiment. Journal of Public Economics, forthcoming.

Brambor, T., Clark, W. R., Golder, M., 2006. Understanding Interaction Models: Improving Empirical Analyses. Political Analysis 14 (1), 63-82.

Brams, S. J., Fishburn, P. C., 1978. Approval Voting. American Political Science Review 72 (3), 831-847.

Brams, S. J., Fishburn, P. C., 2005. Going from Theory to Practice: The Mixed Success of Approval Voting. Social Choice and Welfare 25 (2), 457-474.

Brams, S. J., Fishburn, P. C., Merrill, S., 1988. The Responsiveness of Approval Voting: Comments on Saari and Van Newenhizen. Public Choice 59, 121-131.

Buenrostro, L., Dhillon, A., Vida, P., 2013. Scoring Rule Voting Games and Dominance Solvability. Social Choice and Welfare 40 (2), 329-352.

Cox, G. W., 1997. Making votes count: strategic coordination in the world's electoral systems. Vol. 7. Camebridge: Cambridge University Press.

de Borda, J. C., 1781. Mémoire Sur Les Élections Au Scrutin. Histoire et Mémoires de l'Académie Royale des Sciences, 657-665. 
Dellis, A., 2010. Weak Undominance in Scoring Rule Elections. Mathematical Social Sciences 59 (1), 110-119.

Dellis, A., D’Evelyn, S. T., Sherstyuk, K., 2011. Multiple Votes, Ballot Truncation and the Two-Party System: An Experiment. Social Choice and Welfare 37 (2), 171-200.

Dhillon, A., Lockwood, B., 2004. When are Plurality Rule Voting Games Dominance-Solvable? Games and Economic Behavior 46 (1), 55-75.

Duverger, M., 1954. Political Parties. North B and North R Methuen and Company, London.

Erev, I., Roth, A. E., 1998. Predicting How People Play Games: Reinforcement Learning in Experimental Games With Unique, Mixed Strategy Equilibria. American Economic Review, 848-881.

Farquharson, R., 1969. Theory of Voting. New Haven: Yale University Press.

Feddersen, T., 2008. Strategic voting. In: Durlauf, S. N., Blume, L. E. (Eds.), The New Palgrave Dictionary of Economics. Palgrave Macmillan, Basingstoke.

Fiorina, M. P., 1981. Retrospective Voting in American National Elections. New Haven: Yale University Press.

Fischbacher, U., 2007. z-Tree: Zurich Toolbox for Ready-Made Economic Experiments. Experimental Economics 10 (2), 171-178.

Fishburn, P. C., 1978a. Axioms for Approval Voting: Direct Proof. Journal of Economic Theory 19 (1), 180-185.

Fishburn, P. C., 1978b. Symmetric and Consistent Aggregation with Dichotomous Voting. In: Laffont, J.-J. (Ed.), Aggregation and Revelation of Preferences. North-Holland.

Forsythe, R., Myerson, R. B., Rietz, T. A., Weber, R. J., 1993. An Experiment on Coordination in Multi-Candidate Elections: The Importance of Polls and Election Histories. Social Choice and Welfare $10(3), 223-247$.

Forsythe, R., Rietz, T. A., Myerson, R. B., Weber, R. J., 1996. An Experimental Study of Voting Rules and Polls in Three-Candidate Elections. International Journal of Game Theory 25 (3), 355-383.

Fréchette, G. R., 2012. Session-effects in the laboratory. Experimental Economics 15 (3), 485498.

Gerber, E. R., Morton, R. B., Rietz, T. A., 1998. Minority Representation in Multimember Districts. American Political Science Review 92 (1), 127-144.

Greiner, B., 2004. An Online Recruiting System for Economic Experiments. Forschung und Wissenschaftliches Rechnen GWDG Bericht 63 (2), 79-93.

Kube, S., Puppe, C., 2009. (When and How) Do Voters Try to Manipulate? Experimental Evidence from Borda Elections. Public Choice 139 (1-2), 39-52.

Lago, I., 2008. Rational Expectations or Heuristics? Strategic Voting in Proportional Representation Systems. Party Politics 14 (1), 31-49.

Laslier, J.-F., Van der Straeten, K., 2008. A Live Experiment on Approval Voting. Experimental Economics 11 (1), 97-105. 
Lau, R. R., Redlawsk, D. P., 1997. Voting Correctly. American Political Science Review 91 (3), $585-598$.

Lupia, A., 1994. The Effect of Information on Voting Behavior and Electoral Outcomes: An Exprimental Study of Direct Legislation. Public Choice 78, 65-86.

McKelvey, R. D., Ordeshook, P. C., 1985a. Elections with Limited Information: A Fulfilled Expectations Model Using Contemporaneous Poll and Endorsement Data as Information Sources. Journal of Economic Theory 36, 55-85.

McKelvey, R. D., Ordeshook, P. C., 1985b. Sequential Elections with Limited Information. American Journal of Political Science 29, 480-512.

Merrill, S., Nagel, J., 1987. The Effect of Approval Balloting on Strategic Voting Under Alternative Decision Rules. American Political Science Review 81 (2), 509-524.

Morton, R., Tyran, J.-R., 2010. Let the experts decide? Asymmetric Information, Abstention and Coordination in Standing Committees. Games and Economic Behavior 72, 485-509.

Morton, R. B., Rietz, T. A., 2007. Majority Requirements and Minority Representation. NYU Annual Survey of American Law 63, 691-725.

Moulin, H., 1979. Dominance Solvable Voting Schemes. Econometrica 47 (6), 1137-1151.

Myatt, D. P., 2007. On the Theory of Strategic Voting. Review of Economic Studies 74 (1), $255-281$.

Myerson, R. B., 2000. Large Poisson Games. Journal of Economic Theory 94 (1), 7-45.

Myerson, R. B., 2002. Comparison of Scoring Rules in Poisson Voting Games. Journal of Economic Theory 103 (1), 219-251.

Myerson, R. B., Weber, R. J., 1993. A Theory of Voting Equilibria. American Political Science Review 87 (1), 102-114.

Nagel, J. H., 1 2007. The burr dilemma in approval voting. The Journal of Politics 69 (01), $43-58$.

Niemi, R. G., 1984. The Problem of Strategic Behavior under Approval Voting. American Political Science Review 78 (4), 952-958.

Page, B. I., Shapiro, R. Y., 2010. The rational public: Fifty years of trends in Americans' policy preferences. University of Chicago Press.

Potthoff, R. F., 2011. Condorcet Polling. Public Choice 148 (1-2), 67-86.

Rietz, T. A., Myerson, R. B., Weber, R. J., 1998. Campaign Finance Levels as Coordinating Signals in Three-way, Experimental Elections. Economics \& Politics 10 (3), 185-218.

Riker, W., 1982. Liberalism Against Populism: A Confrontation Between The Theory Of Social Democracy And The Theory Of Social Choice. San Francisco, CA: WH Freeman.

Saari, D. G., 1994. The Geometry of Voting. Berlin: Springer Verlag.

Sears, D. O., Kinder, D., 1985. Public Opinion and Political Action. In: Lindzey, G., Aronson, E. (Eds.), Handbook of Social Psychology. Random House. 
Sinclair, B., Plott, C. R., 2012. From Uninformed to Informed Choices: Voters, Pre-election Polls and Updating. Electoral Studies 31 (1), 83-95.

Van der Straeten, K., Sauger, N., Laslier, J.-F., Blais, A., 2010. Strategic, Sincere and Heuristic Voting Under Four Election Rules: An Experimental Study. Social Choice and Welfare 35 (3), $435-472$.

Wittman, D., 1989. Why Democracies Produce Efficient Results. The Journal of Political Economy 97 (6), 1395-1424.

Wolitzky, A., 2009. Fully Sincere Voting. Games and Economic Behavior 67 (2), 720-735. 


\section{A Additional tables}

Table 6: Fraction of elections won for each alternative under $A V$, in percent.

\begin{tabular}{lrrrrrrrr}
\hline & \multicolumn{4}{c}{ Full Information } & \multicolumn{4}{c}{ No Information } \\
& $\mathrm{A}$ & $\mathrm{B}$ & $\mathrm{C}$ & $\mathrm{D}$ & $\mathrm{A}$ & $\mathrm{B}$ & $\mathrm{C}$ & $\mathrm{D}$ \\
\hline SA & 2.47 & 17.23 & 5.60 & 74.70 & 5.34 & 24.26 & 8.12 & 62.28 \\
SA Last 4 & 3.04 & 13.45 & 3.39 & 80.12 & 4.86 & 21.70 & 7.47 & 65.97 \\
SA Last & 3.47 & 9.03 & 3.47 & 84.03 & 3.47 & 23.61 & 7.64 & 65.28 \\
& & & & & & & & \\
S01 & 2.99 & 20.18 & 6.12 & 70.70 & 5.21 & 21.35 & 8.85 & 64.58 \\
S01 Last 4 & 1.82 & 15.36 & 3.39 & 79.43 & 5.73 & 26.56 & 3.65 & 64.06 \\
S01 Last & 4.17 & 10.42 & 0.00 & 85.42 & 4.17 & 33.33 & 4.17 & 58.33 \\
& & & & & & & & \\
S02 & 1.69 & 14.45 & 3.78 & 80.08 & 2.47 & 29.04 & 5.08 & 63.41 \\
S02 Last 4 & 2.60 & 10.42 & 3.13 & 83.85 & 1.04 & 21.35 & 4.69 & 72.92 \\
S02 Last & 6.25 & 6.25 & 0.00 & 87.50 & 0.00 & 31.25 & 0.00 & 68.75 \\
& & & & & & & & \\
S03 & 2.73 & 17.06 & 6.90 & 73.31 & 8.33 & 22.40 & 10.42 & 58.85 \\
S03 Last 4 & 4.69 & 14.58 & 3.65 & 77.08 & 7.81 & 17.19 & 14.06 & 60.94 \\
S03 Last & 0.00 & 10.42 & 10.42 & 79.17 & 6.25 & 6.25 & 18.75 & 68.75 \\
\hline \hline
\end{tabular}

Note: S0X considers the Xth series, SA considers all three series. Also shown are the figures when considering only the last four elections of the relevant series or only the very last ones. 
Table 7: Fraction of elections won for each alternative under BC, in percent.

\begin{tabular}{lrrrrrrrr}
\hline \hline & \multicolumn{3}{c}{ Full Information } & \multicolumn{5}{c}{ No Information } \\
& $\mathrm{A}$ & $\mathrm{B}$ & $\mathrm{C}$ & $\mathrm{D}$ & $\mathrm{A}$ & $\mathrm{B}$ & $\mathrm{C}$ & $\mathrm{D}$ \\
\hline SA & 6.51 & 6.60 & 13.45 & 73.44 & 5.03 & 9.29 & 13.80 & 71.87 \\
SA Last 4 & 7.29 & 4.34 & 11.81 & 76.56 & 4.51 & 9.90 & 12.33 & 73.26 \\
SA Last & 11.11 & 7.64 & 6.25 & 75.00 & 9.72 & 8.33 & 9.72 & 72.22 \\
& & & & & & & & \\
S01 & 9.11 & 10.94 & 23.44 & 56.51 & 2.86 & 17.97 & 9.90 & 69.27 \\
S01 Last 4 & 10.42 & 6.77 & 20.83 & 61.98 & 4.69 & 23.44 & 14.06 & 57.81 \\
S01 Last & 12.50 & 16.67 & 10.42 & 60.42 & 12.50 & 25.00 & 12.50 & 50.00 \\
& & & & & & & & \\
S02 & 5.21 & 5.21 & 10.42 & 79.17 & 4.69 & 5.99 & 13.02 & 76.30 \\
S02 Last 4 & 7.29 & 4.69 & 7.29 & 80.73 & 3.13 & 3.13 & 15.63 & 78.13 \\
S02 Last & 16.67 & 0.00 & 4.17 & 79.17 & 6.25 & 0.00 & 12.50 & 81.25 \\
& & & & & & & & \\
S03 & 5.21 & 3.65 & 6.51 & 84.64 & 7.55 & 18.49 & 18.49 & 70.05 \\
S03 Last 4 & 4.17 & 1.56 & 7.29 & 86.98 & 5.73 & 7.29 & 7.29 & 83.85 \\
S03 Last & 4.17 & 6.25 & 4.17 & 85.42 & 10.42 & 4.17 & 4.17 & 85.42 \\
\hline \hline
\end{tabular}

Note: S0X considers the Xth series, SA considers all three series. Also shown are the figures when considering only the last four elections of the relevant series or only the very last ones.

Table 8: Fraction of elections won for each alternative under PV, in percent.

\begin{tabular}{lrrrrrrrr}
\hline \hline & \multicolumn{4}{c}{ Full Information } & \multicolumn{5}{c}{ No Information } \\
& $\mathrm{A}$ & $\mathrm{B}$ & $\mathrm{C}$ & $\mathrm{D}$ & $\mathrm{A}$ & $\mathrm{B}$ & $\mathrm{C}$ & $\mathrm{D}$ \\
\hline SA & 7.29 & 34.90 & 4.17 & 53.65 & 19.10 & 46.53 & 25.35 & 9.03 \\
SA Last 4 & 12.29 & 25.42 & 2.50 & 59.79 & 22.92 & 29.69 & 29.69 & 17.71 \\
SA Last & 7.50 & 22.50 & 5.00 & 65.00 & 20.83 & 29.17 & 29.17 & 29.17 \\
& & & & & & & & \\
S01 & 6.25 & 36.20 & 7.29 & 50.26 & 28.12 & 42.45 & 24.22 & 5.21 \\
S01 Last 4 & 12.50 & 29.69 & 6.25 & 51.56 & 25.56 & 34.38 & 29.69 & 9.38 \\
S01 Last & 6.25 & 18.75 & 12.50 & 62.50 & 25.00 & 18.75 & 31.25 & 25.00 \\
& & & & & & & & \\
S02 & 8.85 & 49.48 & 0.00 & 41.67 & 3.13 & 51.56 & 34.38 & 10.94 \\
S02 Last 4 & 14.58 & 36.46 & 0.00 & 48.96 & 1.56 & 39.06 & 37.50 & 21.88 \\
S02 Last & 0.00 & 50.00 & 0.00 & 50.00 & 0.00 & 37.50 & 37.50 & 25.00 \\
& & & & & & & & \\
S03 & 7.55 & 26.30 & 3.13 & 63.02 & 26.04 & 45.57 & 17.45 & 10.94 \\
S03 Last 4 & 10.94 & 15.63 & 0.00 & 73.44 & 40.63 & 15.63 & 21.88 & 21.88 \\
S03 Last & 12.50 & 12.50 & 0.00 & 75.00 & 37.50 & 6.25 & 18.75 & 37.50 \\
\hline \hline
\end{tabular}

Note: S0X considers the Xth series, SA considers all three series. Also shown are the figures when considering only the last four elections of the relevant series or only the very last ones. 
Table 9: Relative frequencies of ballot cast in the experiment in percent.

\begin{tabular}{lrrrrrrrr} 
& \multicolumn{2}{c}{ Type I } & \multicolumn{2}{c}{ Type II } & \multicolumn{2}{c}{ Type III } & \multicolumn{2}{c}{ Total } \\
& AVFI & AVNI & AVFI & AVNI & AVFI & AVNI & AVFI & AVNI \\
\hline Top & 19.3 & 37.8 & 49.5 & 58.2 & 25.3 & 28.4 & 33.9 & 43.8 \\
Top Two & 45.3 & 51.3 & 32.6 & 28.6 & 52.1 & 54.2 & 41.8 & 42.4 \\
Top Three & 13.5 & 6.5 & 4.0 & 6.3 & 6.8 & 7.6 & 7.5 & 6.7 \\
Top Third & 2.3 & 0.5 & 0.9 & 1.0 & 0.8 & 3.9 & 1.3 & 1.7 \\
D only & 10.9 & 0.5 & 4.9 & 1.2 & 6.8 & 1.3 & 7.1 & 1.0 \\
Other & 8.6 & 3.4 & 8.2 & 4.7 & 8.3 & 4.7 & 8.3 & 4.3
\end{tabular}

\begin{tabular}{lrrrrrrrr} 
& \multicolumn{2}{c}{ Type I } & \multicolumn{2}{c}{ Type II } & \multicolumn{2}{c}{ Type III } & \multicolumn{2}{c}{ Total } \\
& BCFI & BCNI & BCFI & BCNI & BCFI & BCNI & BCFI & BCNI \\
\hline Sincere & 45.6 & 45.8 & 39.1 & 50.3 & 42.7 & 41.4 & 42.0 & 46.5 \\
TopWorst $>0$ & 16.9 & 17.7 & 20.7 & 26.0 & 28.4 & 26.8 & 21.8 & 23.9 \\
Second & 25.5 & 25.8 & 28.0 & 18.4 & 20.6 & 12.0 & 25.1 & 18.7 \\
TopWorst $=0$ & 4.7 & 6.8 & 3.1 & 3.6 & 6.5 & 13.8 & 4.5 & 7.4 \\
Other & 7.3 & 3.9 & 9.2 & 1.6 & 1.8 & 6.0 & 6.5 & 3.5
\end{tabular}

\begin{tabular}{|c|c|c|c|c|c|c|c|c|}
\hline & \multicolumn{2}{|c|}{ Type I } & \multicolumn{2}{|c|}{ Type II } & \multicolumn{2}{|c|}{ Type III } & \multicolumn{2}{|c|}{ Total } \\
\hline & PVFI & PVNI & PVFI & PVNI & PVFI & PVNI & PVFI & PVNI \\
\hline Top & 27.2 & 64.1 & 85.2 & 87.7 & 31.0 & 69.8 & 53.1 & 75.8 \\
\hline Second & 66.6 & 10.7 & 12.1 & 8.9 & 54.7 & 10.4 & 39.8 & 9.8 \\
\hline Third & 4.1 & 24.2 & 2.1 & 1.4 & 11.3 & 18.2 & 5.3 & 12.7 \\
\hline Other & 2.2 & 1.0 & 0.6 & 2.1 & 3.1 & 1.6 & 1.8 & 1.6 \\
\hline
\end{tabular}

Note: Categories are mutually exclusive. AV - Top: approve of the most preferred alternative, Top Two: approve of the two most preferred alternatives, Top Three: approve of the three most preferred alternatives, Top Third: approve of the most and the third most preferred alternatives, D only: approve of D only, Other: remaining ballots; BC - Sincere: sincere ballots, Top Worst $>0$ : admissible ballots in which the most preferred alternative receives 3 points and the least preferred one receives more than 0 points, Second: admissible ballots in which the most preferred alternative receives 2 points, TopWorst $=0$ : non-sincere ballots in which the most preferred alternative receives 3 points and the least preferred one receives 0 points, Other: remaining ballots; PV - Top: ballots cast for the most preferred alternative, Second: ballots cast for the second most preferred alternative, Third: ballots cast for third most preferred alternative, Other: ballots cast for the last preferred alternative. 


\section{B Experimental materials}

The original experimental instructions were written in German.

\section{B.1 Instructions full information: English}

Welcome to the experiment. Please read the following instructions carefully. In case there is something you do not understand now or during the course of the experiment, please raise your hand. An assistant will come to you and answer your questions.

The experiment consists of two parts, a decision part and a questionnaire. In the first part, you will participate in a series of elections and each of your voting decisions constitutes a round in the experiment. For this purpose, you will form a group with six other, randomly chosen participants. Within this group, one election will be held in each round of the experiment. There are four available alternatives, A, B, C, and D for which you can vote for.

Approval Voting:

The voting method employed in each election is called 'Approval Voting'. Under Approval Voting you may vote for several alternatives simultaneously, however, you may give each alternative at most one vote. That is, you can approve of as many alternatives as you wish. Note that approvals are not weighted. Each alternative you approve of receives one vote. The alternative with the most approvals is declared the winner of the election. In case that more than one alternative receives the most approvals, one of these alternatives will be randomly selected as the winner of the election. Please notice that you cannot abstain.

Borda Count:

The voting method employed in each election is called 'Borda Count'. Under Borda Count you allot points among the alternatives. In each election, you give 3 points to one of the four alternatives, 2 points to one (other) alternative, 1 point to one (other) alternative and finally zero points to the remaining alternative. Assigning points is your decision and completely up to you. The points each alternative receives are summed and the alternative with the most points is declared the winner of the election. In case that more than one alternative receives the most points, one of these alternatives will be randomly selected as the winner of the election. Please notice that you cannot abstain.

Plurality Voting:

The voting method employed in each election is called 'Plurality Voting'. Under Plurality Voting each member of your group holds exactly one vote which he can assign to one of the four alternatives. The alternative with the most votes is declared the winner of the election. In case that more than one alternative receives the most votes, one of these alternatives will be randomly selected as the winner of the election. Please notice that you cannot abstain.

It is important to note that, in each round, you receive a payoff of experimental currency units (ECU) depending on the election results, i.e., which alternative is declared the winner of the election. It does not matter whether you voted for the winner or not (this sentence was not shown in the Borda Count treatment). The amount you get is solely determined by the winner of the election.

After all participants have voted, a separate screen will appear. This screen contains information about the election results and the payment (ECU) you receive in this round. After displaying the information, a new round will start.

You will participate in 8 elections. During these 8 elections, the group composition and the payoffs you can receive are held fixed (your own payoff as well as the other group members' payoffs). After the 8 elections, new groups are built. Again, you and six other, randomly chosen participants form a new group. You receive new payoffs and 8 further elections will be held. This procedure is repeated twice. In total, you will participate in 24 elections. 
At the end of the experiment, the sum of your payoffs over all rounds is taken. Each ECU you receive is exactly worth 0.6 EURO-CENTS (hence 100 ECU are worth 60 EURO-CENTS). You will be payed in cash and privately, so the other participants will not know how much money you receive.

The decision screen later in the experiment will display several elements. We added a screenshot of the decision screen to the instructions exemplifying these elements. The numbers that you can see on the picture are just here to help you understand the different elements. The numbers that you will see on the screen during the actual experiment will be different from the ones shown here. However, the placement of the elements will be the same. A step by step explanation is given on page 2 of the instructions.

On the left side of the screen, you can see two boxes. They provide information about the payoffs within your group and the payoffs you can receive. The upper box shows the entire payoff schedule of your group. The rows of the table within this box are read as follows:

Your group consists of:

- 2 participants, each one receiving 1 ECU if alternative A wins the elections, 2 ECU if alternative $\mathrm{B}$ wins, $3 \mathrm{ECU}$ if alternative $\mathrm{C}$ wins, and 4 ECU if alternative $\mathrm{D}$ wins.

- 3 participants, each one receiving $3 \mathrm{ECU}$ if alternative $\mathrm{A}$ wins the elections, $2 \mathrm{ECU}$ if alternative $\mathrm{B}$ wins, $4 \mathrm{ECU}$ if alternative $\mathrm{C}$ wins, and $1 \mathrm{ECU}$ if alternative $\mathrm{D}$ wins.

- 2 participants, each one receiving $4 \mathrm{ECU}$ if alternative $\mathrm{A}$ wins the elections, $3 \mathrm{ECU}$ if alternative $\mathrm{B}$ wins, 2 ECU if alternative $\mathrm{C}$ wins, and 1 ECU if alternative $\mathrm{D}$ wins.

So, the first number in a line always tells you how many participants you have in your group who are characterized by the payoff figures following this first number. The table in this box is the same for all participants. Importantly, this means your own payoffs are also included in this table.

The lower box on the left-hand side provides you with information about your payoffs and is read as follows:

If:

- Alternative A wins the election, you receive 1 ECU

- Alternative $\mathrm{B}$ wins the election, you receive 2 ECU

- Alternative $\mathrm{C}$ wins the election, you receive $3 \mathrm{ECU}$

- Alternative $\mathrm{D}$ wins the election, you receive $4 \mathrm{ECU}$

During the experiment, you will have more than enough time to process the information. Approval Voting:

In the middle of the screen you can see 2 more boxes. Your voting decisions are made in the top box. Here, you decide which alternatives you would like to approve of. Keep in mind that under Approval Voting, you can approve of as many alternatives as you wish. The alternative with the most approvals is declared the winner of the election. You can mark the alternatives you approve of by clicking the corresponding check-boxes, i.e., setting a tick in the white boxes next to the alternatives. Note that in order to finally submit your vote, you have to click on the next button. So, please set your approvals first, and then, after having done the marking, click on the next button to confirm your vote. When every participant has confirmed his vote, the next screen appears showing the election results and your payoff for this round. 


\section{Borda Count:}

In the middle of the screen you can see 2 more boxes. Your voting decisions are made in the top box. Here, you decide how to allot the points among the alternatives. Keep in mind that your task is to give 3 points to one of the four alternatives, 2 points to one (other) alternative, 1 point to one (other) alternative and finally zero points to the remaining alternative. The points each alternative receives are summed and the alternative with the most points is declared the winner of the election. Note that in order to finally submit your allotted points, you have to click on the next button. So, please allot your points first, and then click on the next button to confirm your allotted points. When every participant has confirmed his allotted points, the next screen appears showing the election results and your payoff for this round.

Plurality Voting:

In the middle of the screen you can see 2 more boxes. Your voting decisions are made in the top box. Here, you decide which alternatives you would like to vote for. Keep in mind that under Plurality Voting, you assign exactly one vote and the alternative with the most votes is declared the winner of the election. You can mark the alternative you would like to vote for by clicking the corresponding white circle. Note that in order to finally submit your vote, you have to click on the next button. So, please assign your vote first, and then, after having done the marking, click on the next button to confirm your vote. When every participant has confirmed his vote, the next screen appears showing the election results and your payoff for this round.

The lower box in the middle gives you information about the results of the past elections in your group. Here, you can see how many participants from your group approved of the alternatives A, B, C and D in the last elections. At first, this box will be empty.

\section{B.2 Instructions full information: German}

Willkommen zum Experiment. Bitte lesen Sie die folgende Anleitung sorgfältig durch. Falls Sie jetzt oder im Laufe des Experiments etwas nicht verstehen, heben Sie bitte die Hand. Ein Mitarbeiter wird dann an Ihren Platz kommen, um Ihre Fragen zu beantworten.

Das Experiment besteht aus 2 Teilen, einem Entscheidungsteil und einem anschließenden Fragebogen. Im Entscheidungsteil werden Sie an einer Reihe von Wahlen teilnehmen, wobei jede einzelne Ihrer Wahlentscheidungen eine Runde des Experiments darstellt. Hierzu werden Sie mit sechs weiteren, zufällig ausgesuchten Teilnehmern eine Gruppe bilden. Innerhalb dieser Gruppe finden dann in jeder Runde die Wahlen statt. Es stehen Ihnen generell 4 Alternativen, A, B, C und D, zur Auswahl, für die Sie stimmen können.

Approval Voting:

Die Wahlmethode, die in jeder Wahl angewendet wird ist das sogenannte "Zustimmungsverfahren". Beim Zustimmungsverfahren kann für mehrere Alternativen gleichzeitig gestimmt werden, jedoch nicht mehrmals für ein und dieselbe. Sie können also so vielen Alternativen Ihre Zustimmung geben, wie Sie möchten. Hierbei wird keine Gewichtung vorgenommen. Jede Alternative, der Sie zustimmen, erhält eine volle Stimme. Der Gewinner der Runde in Ihrer Gruppe ist die Alternative, die die meisten Zustimmungen erhält. Sollte mehr als eine Alternative die meisten Zustimmungen in einer Runde erhalten, wird zufällig bestimmt, welche dieser Alternativen der Gewinner der Wahl ist. Bitte beachten Sie, dass Sie sich nicht enthalten können.

Borda Count:

Die Wahlmethode, die in jeder Wahl angewendet wird ist die sogenannte "Borda-Wahl". Bei der Borda Wahl verteilen Sie Punkte an die Alternativen. In jeder Wahl bekommt eine der vier Alternative von Ihnen 3 Punkte zugewiesen, eine (andere) Alternative 2 Punkte, eine (andere) Alternative 1 Punkt und schließlich die verbleibende Alternative 0 Punkte. Welcher Alternative Sie wie viele Punkte geben ist allein Ihre Entscheidung. Die Punkte, die eine Alternative von 
den Teilnehmern bekommen hat werden dann addiert und die Alternative mit den meisten Punkten ist dann der Gewinner der Wahl. Sollte mehr als eine Alternative die meisten Punkte in einer Runde erhalten, wird zufällig bestimmt, welche dieser Alternativen der Gewinner der Wahl ist.

Plurality Voting:

Die Wahlmethode, die in jeder Wahl angewendet wird ist die sogenannte "Einfache Mehrheitswahl". Bei der Einfachen Mehrheitswah hat jeder Teilnehmer Ihrer Gruppe genau eine Stimme, die er einer der 4 Alternativen geben kann. Der Gewinner der Runde in Ihrer Gruppe ist diejenige Alternative, die die meisten Stimmen erhält. Sollte mehr als eine Alternative die meisten Stimmen in einer Runde erhalten, wird zufällig bestimmt, welche dieser Alternativen der Gewinner der Wahl ist. Bitte beachten Sie, dass Sie sich nicht enthalten können. Das heißt, Sie müssen in jeder Runde einer der 4 Alternativen Ihre Stimme geben.

Wichtig ist, dass Sie in jeder Runde, bedingt auf den Wahlausgang, das heißt je nachdem welche Alternative die Wahl gewonnen hat, eine Auszahlung an Experimentellen Geldeinheiten (EGE) erhalten. Hierbei spielt es keine Rolle, ob Sie für den Gewinner gestimmt haben oder nicht (this sentence was not shown in the Borda Count treatment). Die Höhe Ihrer Auszahlung wird ausschließlich durch den Gewinner der Wahl bestimmt.

Nachdem alle Gruppenmitglieder Ihre Stimme in einer Runde abgegeben haben, erscheint ein separater Bildschirm. Auf diesem erhalten Sie dann die Informationen über den Wahlausgang und Ihre Auszahlung an EGE in dieser Runde. Nachdem Ihnen die Informationen mitgeteilt wurden, startet eine neue Wahl.

Sie werden an 8 Wahlen teilnehmen. Die Gruppenzusammensetzung und die Auszahlungen bleiben über diese 8 Wahlen konstant (sowohl die eigenen als auch die Auszahlungen der anderen Gruppenmitglieder). Nach Abschluss der 8 Wahlen werden die Gruppen neu formiert. Sie werden wieder mit sechs zufällig ausgesuchten Teilnehmern eine neue Gruppe bilden. Sie erhalten neue Auszahlungen und nehmen wiederum an 8 weiteren Wahlen teil. Dies geschieht 2 mal, so dass Sie insgesamt an 24 Wahlen teilnehmen werden.

Nach Abschluss des Experiments wird die Summe der EGE Auszahlungen aller Runden gebildet. Für die Auszahlung in EURO erhalten Sie für jede EGE genau 0,6 EURO-CENTS (100 EGE entsprechen demnach 60 EURO-CENTS). Sie werden bar und privat ausgezahlt und kein anderer Teilnehmer wird erfahren, wie viel Geld Sie erhalten.

Da sich auf dem Computerbildschirm mehrere Elemente befinden werden, haben wir für Sie den Instruktionen ein Beispielfoto des Entscheidungsbildschirms beigelegt. Selbstverständlich dienen die Zahlen auf dem Foto nur dazu, Ihnen die einzelnen Elemente näher zu bringen. Die tatsächlichen Zahlen auf dem Computerbildschirm im Experiment werden sich von denen des Beispiels hier unterscheiden. Die Anordnung der einzelnen Kästen hingegen werden Sie so auch im Experiment vorfinden. Die Elemente des Bildschirms werden nun Stück für Stück auf Seite 2 der Instruktionen anhand des Beispielfotos erklärt.

Auf der linken Seite des Bildschirms befinden sich zwei separate Kästen. Diese geben Ihnen Informationen über die Auszahlungen des Experiments für Ihre Gruppe und für Sie selber wieder. Der obere der beiden Kästen zeigt Ihnen die Auszahlungen der Gruppe, in der Sie sich befinden. Die Zeilen, der in diesem Kasten dargestellten Tabelle auf dem Beispielfoto lesen sich wie folgt:

In Ihrer Gruppe befinden sich: 2 Teilnehmer, die je 1 EGE erhalten, wenn Alternative A die Wahl gewinnt, je 2 EGE erhalten, wenn Alternative B die Wahl gewinnt, je 3 EGE erhalten, wenn Alternative $\mathrm{C}$ die Wahl gewinnt und je 4 EGE erhalten, wenn Alternative D die Wahl gewinnt 3 Teilnehmer, die je 3 EGE erhalten, wenn Alternative A die Wahl gewinnt, je 2 EGE erhalten, wenn Alternative B die Wahl gewinnt, je 4 EGE erhalten, wenn Alternative C die Wahl gewinnt und 1 EGE erhalten, wenn Alternative D die Wahl gewinnt 2 Teilnehmer, die je 4 EGE erhalten, wenn Alternative A die Wahl gewinnt, je 3 EGE erhalten, wenn Alternative 
B die Wahl gewinnt, je 2 EGE erhalten, wenn Alternative C die Wahl gewinnt und je 1 EGE erhalten, wenn Alternative D die Wahl gewinnt

Die erste Zahl in einer Zeile gibt also immer an, wie viele Teilnehmer sich in Ihrer Gruppe befinden, die die durch die nächsten Zahlen in dieser Zeile beschriebenen Auszahlungen aufweisen. Die Tabelle in diesem Kasten ist für alle Teilnehmer gleich. Das bedeutet insbesondere, dass auch Ihre eigenen Auszahlungen in dieser Tabelle enthalten sind.

Der untere Kasten auf der linken Seite gibt Ihnen Auskunft über Ihre Auszahlung und liest sich wie folgt:

Wenn: Alternative A die Wahl gewinnt, erhalten Sie 1 EGE Alternative B die Wahl gewinnt, erhalten Sie 2 EGE Alternative C die Wahl gewinnt, erhalten Sie 3 EGE Alternative D die Wahl gewinnt, erhalten Sie 4 EGE

Sie werden während des Experiments genug Zeit erhalten, um sich die Informationen anzuschauen. Approval Voting:

In der Mitte sehen Sie 2 weitere Kästen. Im oberen Kasten in der Mitte treffen Sie Ihre Wahlentscheidungen, d.h. Welchen Alternativen Sie zustimmen möchten. Denken Sie daran, dass Sie beim "Zustimmungsverfahren" so vielen Alternativen zustimmen können, wie Sie möchten. Am Ende gewinnt die Alternative die Wahl, welche die meisten Zustimmungen erhält. Markieren Sie bitte in diesem Kasten die Alternativen denen Sie zustimmen möchten, in dem Sie durch einen Klick in den entsprechenden weißen Boxen einen Haken setzten. Die Stimmabgabe wird erst dann endgültig registriert, wenn Sie auf den Weiter-Button klicken. Wir bitten Sie also zuerst Ihre Zustimmungen abzugeben und erst, nachdem Sie die Markierungen gesetzt haben, Ihre Stimmabgabe mit einen Klick auf den Weiter-Button zu bestätigen. Erst wenn alle Teilnehmer ihre Stimmabgabe bestätigt haben, erscheint der nächste Bildschirm mit den Informationen über den Wahlausgang und Ihre Auszahlung für diese Runde.

Borda Count:

In der Mitte sehen Sie 2 weitere Kästen. Im oberen Kasten in der Mitte treffen Sie Ihre Wahlentscheidungen, d.h. wie Sie die Punkte für die Alternativen verteilen möchten. Denken Sie daran, dass Sie einer der vier Alternativen 3 Punkte zuweisen sollen, einer (anderen) Alternative 2 Punkte, einer (anderen) Alternative 1 Punkt und schließlich der verbleibenden Alternative 0 Punkte. Die Punkte, die eine Alternative von den Teilnehmern bekommen hat werden dann addiert und die Alternative mit den meisten Punkten ist dann der Gewinner der Wahl. Die Punktevergabe wird erst dann endgültig registriert, wenn Sie auf den WeiterButton klicken. Wir bitten Sie also zuerst Ihre Punkte zu verteilen und durch einen Klick auf den Weiter-Button zu bestätigen. Erst wenn alle Teilnehmer ihre Punkteverteilung bestätigt haben, erscheint der nächste Bildschirm mit den Informationen über den Wahlausgang und Ihre Auszahlung für diese Runde.

Plurality Voting:

In der Mitte sehen Sie 2 weitere Kästen. Im oberen Kasten in der Mitte treffen Sie Ihre Wahlentscheidungen, d.h. welcher der Alternativen Sie Ihre Stimme geben möchten. Denken Sie daran, dass Sie bei der "einfachen Mehrheitswahl" genau eine Stimme abgeben sollen und am Ende die Alternative die Wahl gewinnt, die die meisten Stimmen auf sich vereint. Markieren Sie bitte in diesem Kasten die Alternative, für die Sie stimmen möchten, indem Sie in den entsprechenden weißen Kreis klicken. Die Stimmabgabe wird erst dann endgültig registriert, wenn Sie auf den Weiter-Button klicken. Wir bitten Sie also zuerst Ihre Stimme abzugeben und erst, nachdem Sie die Markierung gesetzt haben, Ihre Stimmabgabe mit einen Klick auf den Weiter-Button zu bestätigen. Erst wenn alle Teilnehmer ihre Stimmabgabe bestätigt haben, erscheint der nächste Bildschirm mit den Informationen über den Wahlausgang und Ihre Auszahlung für diese Runde.

Der untere Kasten in der Mitte gibt Ihnen Auskunft über die Wahlergebnisse der letzten Runden für Ihre Gruppe. Sie sehen hier also, wie viele Teilnehmer aus Ihrer Gruppe in den 
vergangenen Wahlen den Alternativen A, B, C und D, zugestimmt haben. Dieser Kasten wird am Anfang erst einmal leer sein.

\section{B.3 Instructions no information}

The instructions for the no information treatments were essentially identical to the ones for the full information treatments. The only two differences concern the payoff information provided regarding the group schedule. First, all text relating to the group payoff box is eliminated. Second, two additional sentences at the end of the instructions explain the information structure for these treatments:

English: You will not receive any information regarding the payoffs of other group members in the experiment today. The only pieces of information you will receive are the aggregated results from past elections rounds which will be displayed in this box.

German: Zu keinem Zeitpunkt werden Sie Informationen bezüglich der Auszahlungen der anderen Gruppenmitglieder erhalten. Die einzigen Informationen, die Sie erhalten sind die Endergebnisse der Wahlen vergangener Runden, die in diesem Kasten dargestellt werden.

\section{B.4 Decision screens}

Figure 3 shows the example screen-shot supplementing the written instructions for the Approval Voting, full information treatment. It shows the decision screen in the experiment as faced by the participants (replacing the numbers representing the payoffs as described in the main manuscript). Figure 4 shows the outcome information screen participants faced after each election for the Approval Voting, full information treatment (replacing the numbers representing the payoffs as described in the main manuscript). Since actual text is rather sparse on screen, I abstain from presenting all versions of the decision screen and information screen. Note that for the no information treatments, the upper table on the left-hand side is eliminated and the lower table on the left-hand side moves to the top of the screen. This is the only difference between the full information screens and the no information screens. For the Borda Count and Plurality Voting treatment, simply replace the voting method, the brief description thereof and the term 'approvals' with the corresponding text passages as to be found in the written instructions above. 
Figure 3: Example screen-shot of the decision screen supplementing the written instructions.

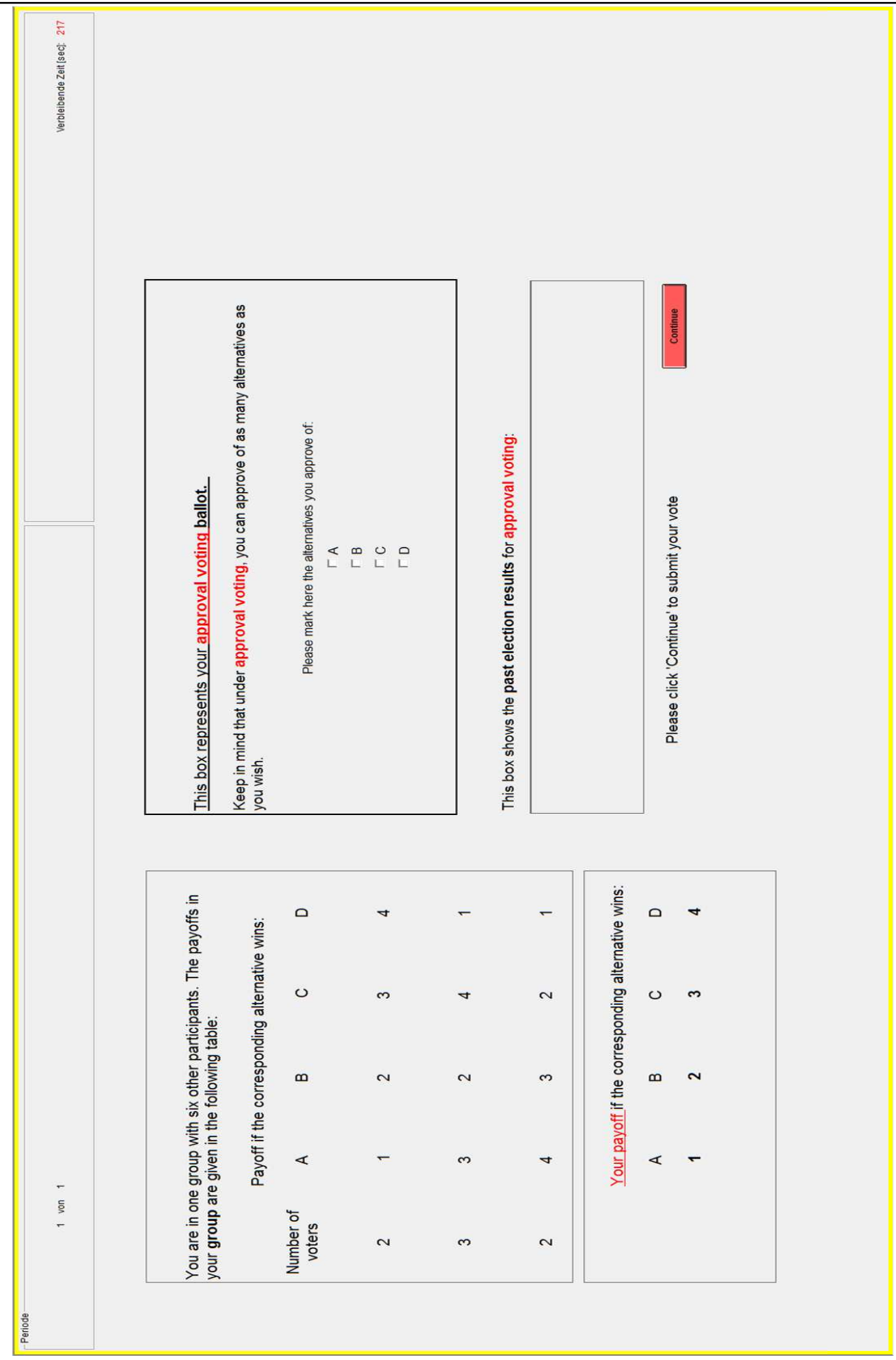


Figure 4: Example screen-shot of the information screen.

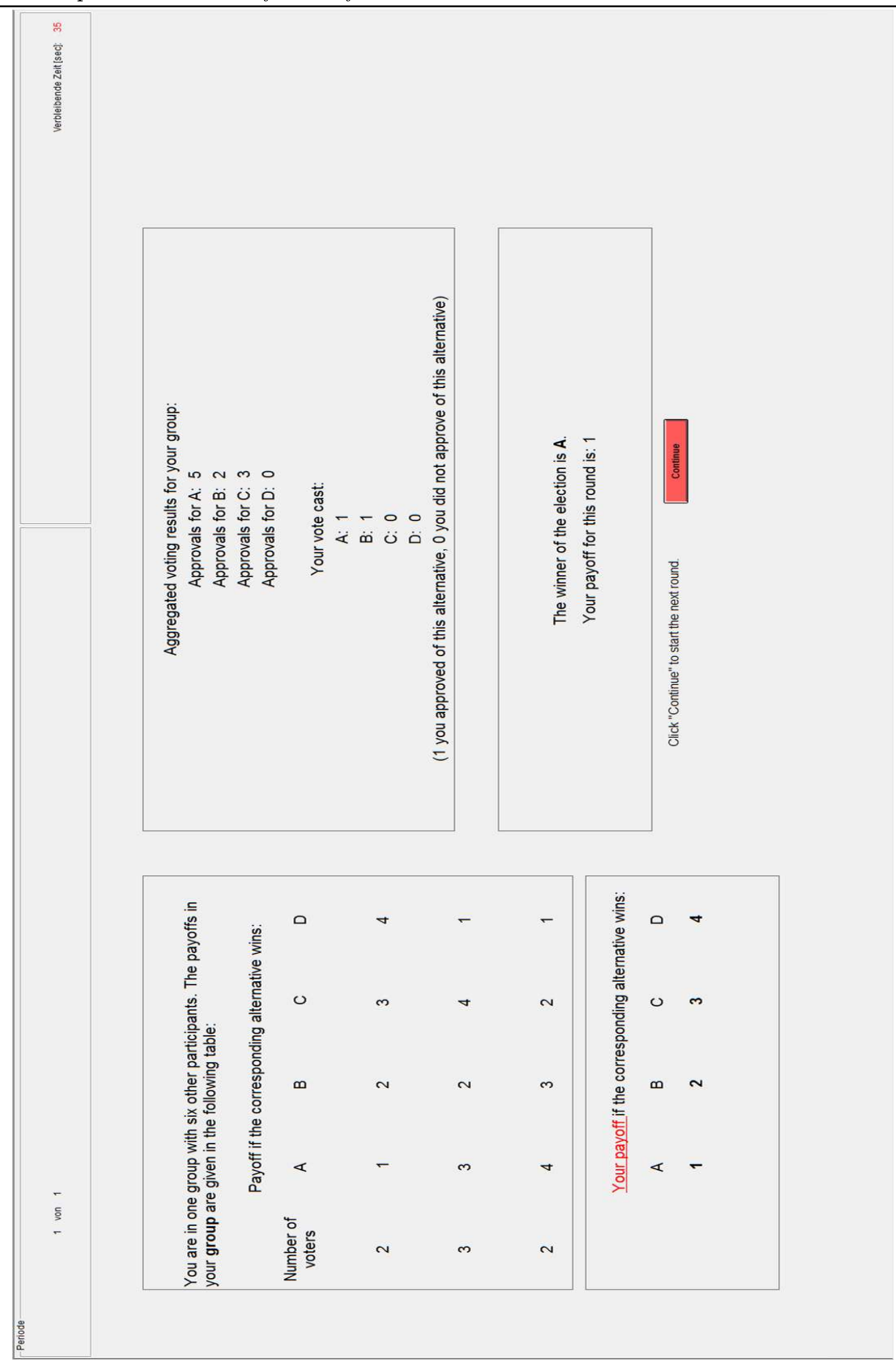




\section{Supplementary online material: additional results and tables}

This document contains the online supplementary materials for the article The Problem of the Divided Majority: Preference Aggregation Under Uncertainty authored by Đura-Georg Granić. The first part, C.1, contains non-parametric test for the main hypothesis of the main manuscript for the independent data of the first series elections. The second part, C.2 contains some additional comments on the game-theoretic analysis of the one-shot voting game given in Section 2.1 of the main text. The final part, C.3, shows additional tables breaking down election results to the individual voting groups for each treatment.

\section{C.1 Non-parametric tests main hypothesis for first series of elections}

The text below present the results from non-parametric tests to confirm the main hypotheses. Due the re-matching procedure employed in the experiment only the first four voting groups in each session are statistically independent. Since 2 sessions per treatment were conducted, the total number of independent observations is $N=8$ per treatment.

Hypothesis $\mathbf{H 1}$ states that the Condorcet winner should win more elections under AV and $\mathrm{BC}$ than under PV with no information. Corroborated by a series of pairwise, two-sided Wilcoxon-Mann-Whitney tests, winning frequencies of $D$ are higher under $\mathrm{AV}$ and $\mathrm{BC}$ than PV. ${ }^{16}$ Applying the same set of test, total welfare is also significantly higher under AV and BC than under PV. ${ }^{17}$

H2a postulates that voting groups mainly implement $D$ under full information. This translate into a series of Wilcoxon-signed-rank tests on the differences in frequencies of won elections between $A, B$, and $C$ combined and $D$. We test the null-hypothesis that the difference is larger or equal to zero, i.e. weakly higher winning frequencies for $A, B$, and $C$ in comparison to $D$. The corresponding tests reject the null-hypothesis in favor of the alternative hypothesis of higher winning frequencies for $D$ under $\operatorname{AV}(N=8, z=-2.10, p=0.020$, median $=-0.479$, mean $=-0.414$, stdev $=0.380)$. The corresponding test does not reject the null-hypothesis under $\mathrm{BC}(N=8, Z=-0.78, p=0.250$, median $=-0.042$, mean $=-0.130$, stdev $=0.480)$. Still, $D$ wins the most elections under $\mathrm{BC}$ in series 1 ( $A: 9 \%, B: 11 \%, C: 23 \%, D: 57 \%)$. The corresponding test also does not reject the null-hypotheses for PV $(N=8, Z=-0.14$, $p=0.473$, median $=-0.166$, mean $=-0.005$, stdev $=0.569)$. As in the case for $\mathrm{BC}, D$ still wins the most election under PV in the first series of elections $(A: 6 \%, B: 36 \%, C: 7 \%, D$ : $50 \%)$.

Hypothesis $\mathbf{H} \mathbf{2 b}$ postulates lower winning frequencies for $D$ under no information than under full information for PV. The huge decline in winning frequencies for $D$ in the no information treatment is statistically significant according to a one-sided Wilcoxon-Mann-Whitney test $(N=16, Z=2.99, p=0.001)$. The observed decline in winning frequencies of $D$ also leads to a significant reduction of welfare levels. According to a one-sided Wilcoxon-Mann-Whitney test, total welfare is significantly greater under full information than under no information $(N=16, Z=2.52, p=0.005)$ Median per election welfare drops from 0.738 under full information $($ mean $=0.643$, stdev $=0.236$ ) to 0.293 under no information (mean $=0.333$, stdev $=0.169)$ in the first series of elections.

\footnotetext{
16 To account for multiple pairwise comparisons p-values reported in this document are adjusted according to the Holm-Bonferroni procedure. AV vs $\mathrm{BC}-N=16, Z=-0.68, p=0.522$; AV vs $\mathrm{PV}: N=16, Z=3.41$, $p<0.001$; BC vs PV: $N=16, Z=3.41, p<0.001$.

$17 \mathrm{AV}$ vs $\mathrm{BC}-N=16, Z=-0.79, p=0.229 ; \mathrm{AV}$ vs $\mathrm{PV}-N=16, Z=3.26, p<0.001 ; \mathrm{BC}$ vs $\mathrm{PV}-N=16$, $Z=3.36, p<0.001$; welfare level: AV - median $=0.710$, mean $=0.741$, stdev $=0.153 ; \mathrm{BC}-$ median $=0.822$, mean $=0.796$, stdev $=0.100 ; \mathrm{PV}-$ median $=0.293$, mean $=0.333$, stdev $=0.169$.
} 
The first part in hypothesis $\mathbf{H 3}$ postulates decreasing winning frequencies of $B$ under PV. The corresponding Cuzick's trend tests reject the null-hypothesis of no trend in favor of the alternative hypothesis of decreasing winning frequencies (FI: $N=8, Z=-1.92, p=0.027$; NI: $N=8, Z=-2.30, p=0.011)$. The second part in hypothesis $\mathbf{H 3}$ postulates that the decrease in $B$ 's wining frequency is sharper under PV than under $\mathrm{AV}$ and $\mathrm{BC}$. We cannot reject the null-hypothesis of no trend for Cuzick's trend tests under BC (FI: $N=8, Z=0.19, p=0.425$; NI: $N=8, Z=0.35, p=0.0 .636)$. Cuzick's trend tests reveal a weakly significant decrease in $B$ 's winning frequency in AVFI and no significant negative trend under AVNI (FI: $N=8$, $Z=-1.51, p=0.065 ; \mathrm{NI}: N=8, Z=1.23, p=0.890)$.

\section{C.2 Iterative elimination of weakly dominated strategies}

Given the induced preference profile in Table 1 all alternatives can be sustained as Nash equilibrium (NE) outcomes of the (one-shot) voting game. For example, in unanimous situations there is no pivotal voter, and hence, no unilateral profitable deviation exists. However, many such profiles include the use of weakly dominated strategies by some players: strategies that under no circumstances yield a strictly better outcome, and in some cases give unequivocally worse outcomes than some other strategies. A common assumption in the literature is to restrict the set of strategies for each player to undominated or admissible strategies narrowing down the set of possible outcomes. For an early account, we refer to the seminal work of Farquharson (1969) and Moulin (1979). More recently, (iterative) elimination of dominated strategies has been applied in scoring rule voting games Dhillon and Lockwood (2004); Dellis (2010); Buenrostro et al. (2013). Table 1 in the main text shows the sincere and admissible strategies as well as the weakly undominated NEs for all three voting methods. ${ }^{18}$

We avoid the path dependence problem, i.e., different orders of eliminations give rise to different solutions, in the elimination process of weakly dominated strategies by identifying all weakly dominated strategies and eliminating of all them simultaneously. As a first step of the elimination process, voting for the least preferred alternative is eliminated for PV, approving of the least preferred alternative and not approving of the most favorable alternative is eliminated for $\mathrm{AV}$, and giving the least preferred alternative more points than the most favorable alternative is eliminated for BC. It is straightforward to see that these strategies are weakly dominated: in pivotal events, they change the outcome in favor of the least favorable option or other strategies exist achieving the same outcome while giving the least preferred option strictly lower support. There are no further (iteratively) dominated strategies.

Under admissibility, alternatives $A, C$ and $D$ are still NE outcomes for AV and PV. This is no longer true for alternative $B$, the Condorcet loser. Suppose $B$ wins the election. The votes $B$ receives in such cases can only come from the three Type II voters who vote for/approve of $B$. Admissibility guarantees the existence of another alternative with at least two votes/approvals. The Condorcet loser is never able to win the election with a margin of two or more. As a consequence, there always exists one voter among the four remaining ones who can alter the outcome of the election to his favor, either by giving rise to a new winner or by letting $B$ tie with another alternative he strictly prefers. Under BC, all four alternatives can be sustained as the outcome in a NE.

\section{C.3 Additional tables}

\footnotetext{
18 As ties can occur, individual preferences over alternatives are extended to preferences over sets of alternatives. I use the standard assumptions $P$ and $R$ from Brams and Fishburn (1978). Assumption $P$ states that, if $x \succ y$ then $x \succ\{x, y\}$ and $\{x, y\} \succ y$. Assumption $R$ states that for every nonempty subset of alternatives $X$, $Y$, and $Z$, if $x \succ y, y \succ z$ and $x \succ z$ for all $x \in X, y \in Y$ and $z \in Z$, then $(X \cup Y) \succeq(Y \cup Z)$.
} 
Table 10: Fraction of won election for all 24 groups of the AVFI treatment.

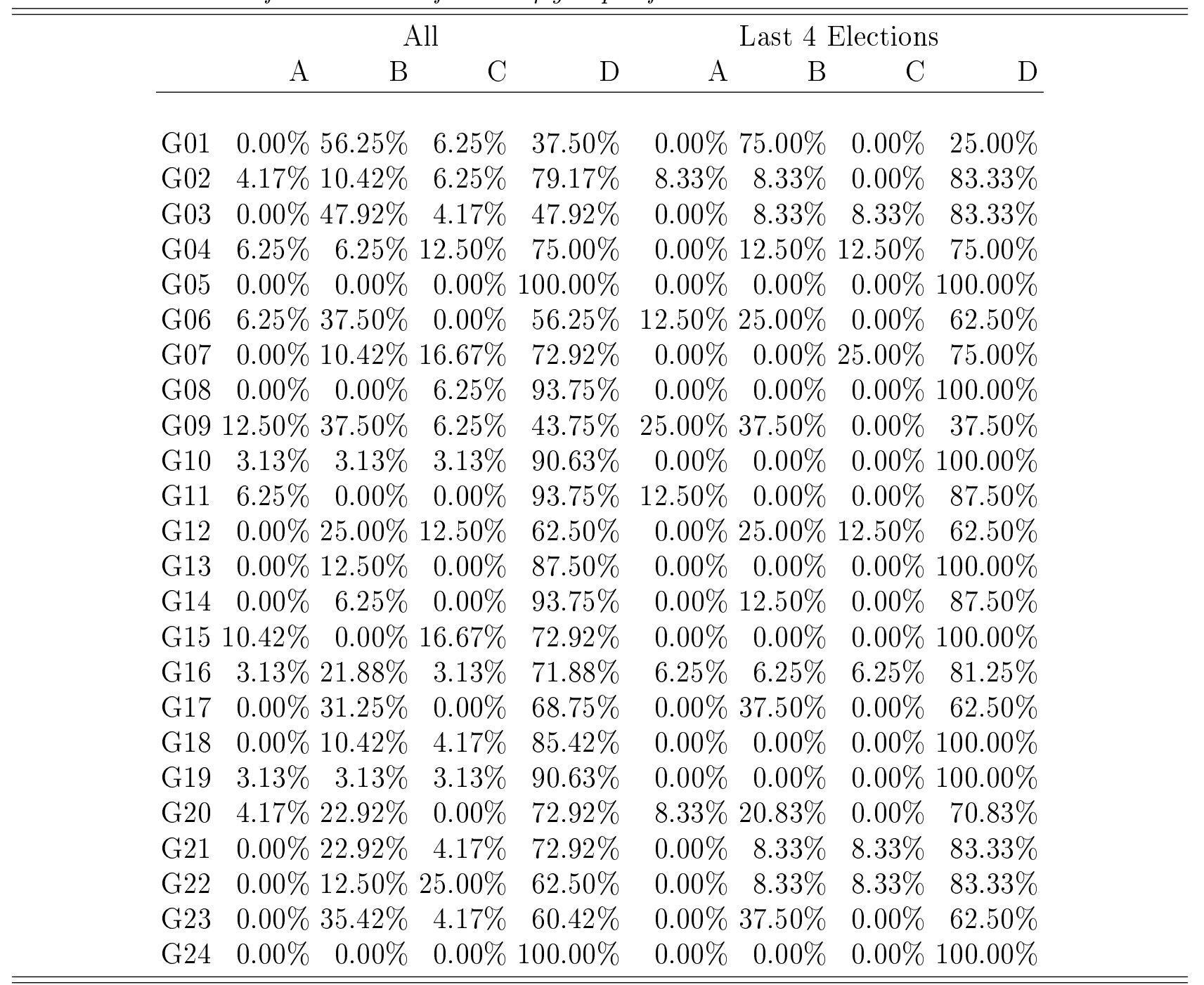

The fraction of won election are shown with respect to all elections within a series or considering only the last 4 elections of a series for all 24 groups of the AVFI treatment. G01 to G12 represent the first session and G13 to G24 the second session of the treatment. 
Table 11: Fraction of won election for all 24 groups of the AVNI treatment.

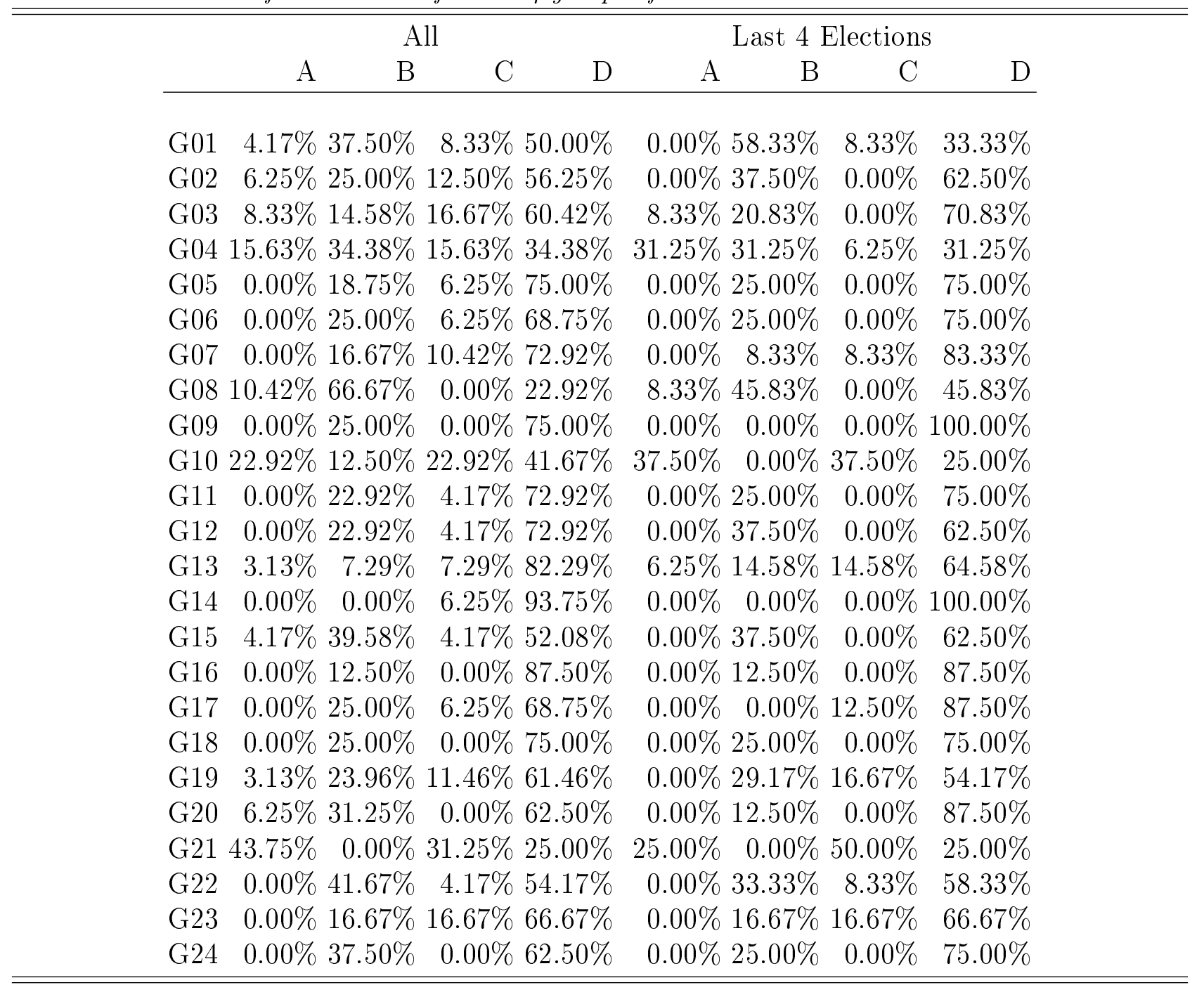

The fraction of won election are shown with respect to all elections within a series or considering only the last 4 elections of a series for all 24 groups of the AVNI treatment. G01 to G12 represent the first session and G13 to G24 the second session of the treatment. 
Table 12: Fraction of won election for all 24 groups of the BCFI treatment.

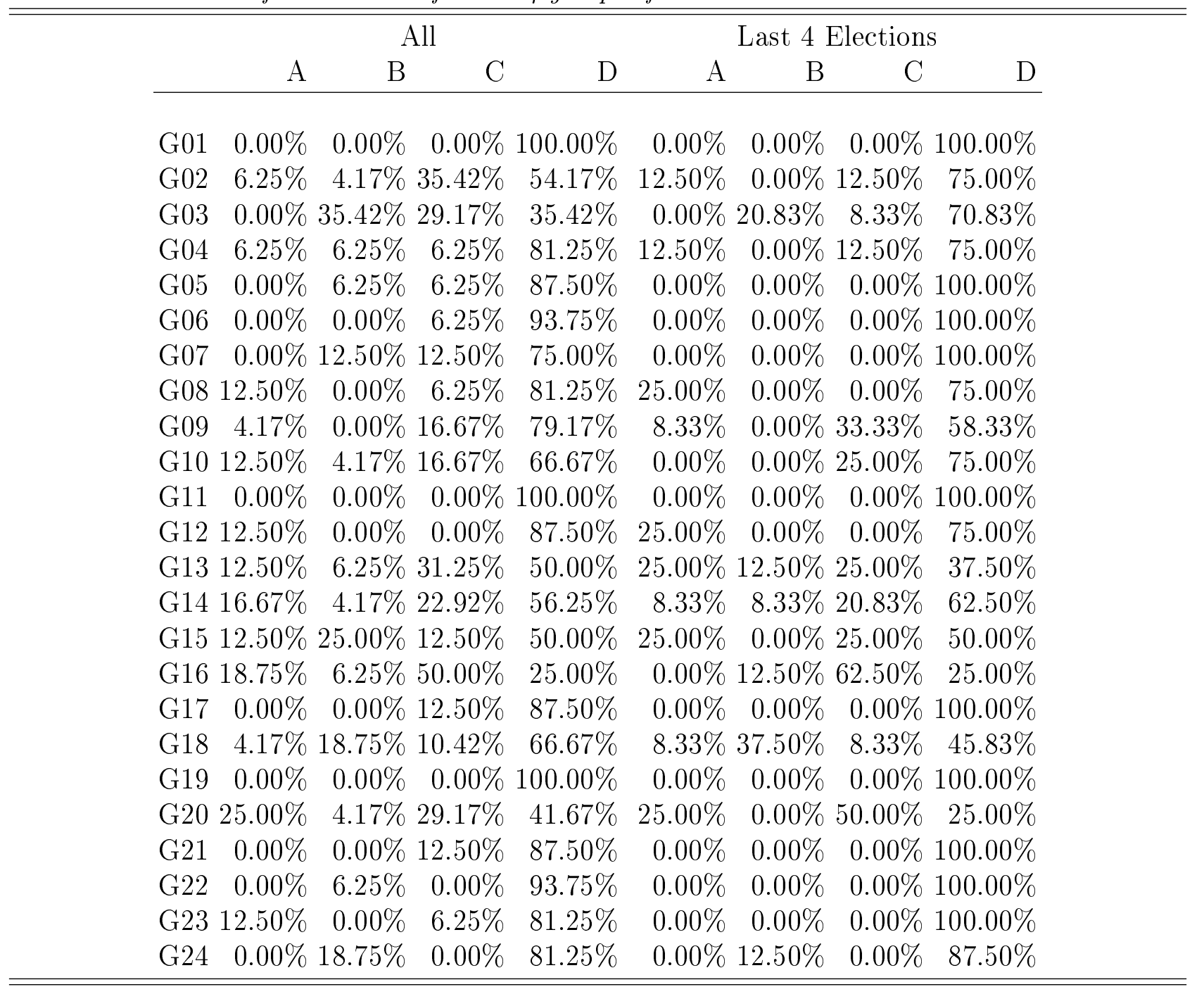

The fraction of won election are shown with respect to all elections within a series or considering only the last 4 elections of a series for all 24 groups of the BCFI treatment. G01 to G12 represent the first session and G13 to G24 the second session of the treatment. 
Table 13: Fraction of won election for all 24 groups of the BCNI treatment.

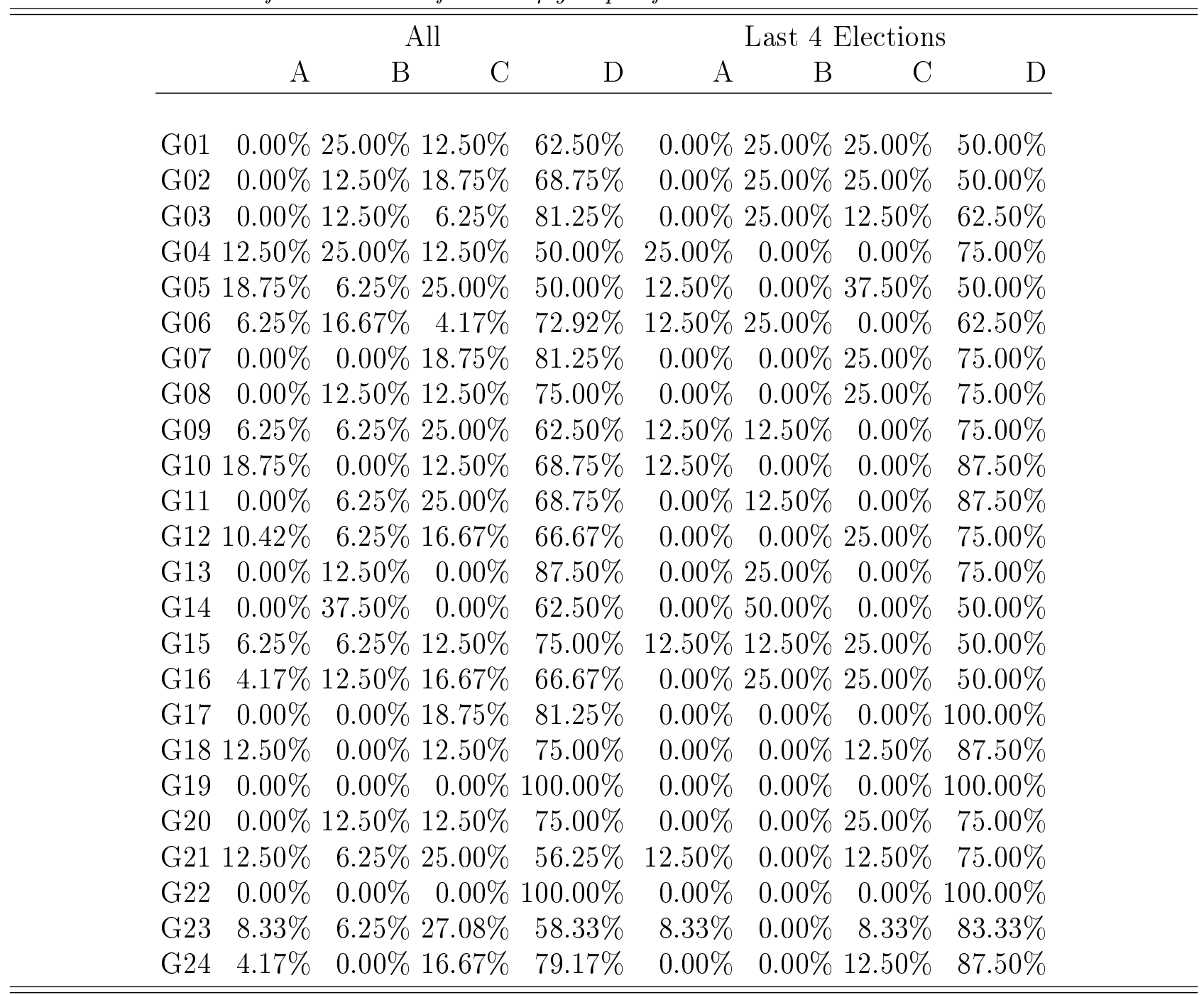

The fraction of won election are shown with respect to all elections within a series or considering only the last 4 elections of a series for all 24 groups of the BCNI treatment. G01 to G12 represent the first session and G13 to G24 the second session of the treatment. 
Table 14: Fraction of won election for all 20 groups of the PVFI treatment.

\begin{tabular}{lcccccccc}
\hline \hline & A & B & C & D & A & B & C & D \\
\hline & \multicolumn{1}{c}{ G } & & & & & & & \\
G01 & $37.50 \%$ & $50.00 \%$ & $0.00 \%$ & $12.50 \%$ & $75.00 \%$ & $0.00 \%$ & $0.00 \%$ & $25.00 \%$ \\
G02 & $0.00 \%$ & $0.00 \%$ & $18.75 \%$ & $81.25 \%$ & $0.00 \%$ & $0.00 \%$ & $25.00 \%$ & $75.00 \%$ \\
G03 & $0.00 \%$ & $18.75 \%$ & $12.50 \%$ & $68.75 \%$ & $0.00 \%$ & $37.50 \%$ & $0.00 \%$ & $62.50 \%$ \\
G04 & $12.50 \%$ & $72.92 \%$ & $10.42 \%$ & $4.17 \%$ & $25.00 \%$ & $75.00 \%$ & $0.00 \%$ & $0.00 \%$ \\
G05 & $4.17 \%$ & $35.42 \%$ & $0.00 \%$ & $60.42 \%$ & $0.00 \%$ & $25.00 \%$ & $0.00 \%$ & $75.00 \%$ \\
G06 & $0.00 \%$ & $25.00 \%$ & $12.50 \%$ & $62.50 \%$ & $0.00 \%$ & $37.50 \%$ & $0.00 \%$ & $62.50 \%$ \\
G07 & $56.25 \%$ & $43.75 \%$ & $0.00 \%$ & $0.00 \%$ & $87.50 \%$ & $12.50 \%$ & $0.00 \%$ & $0.00 \%$ \\
G08 & $0.00 \%$ & $6.25 \%$ & $0.00 \%$ & $93.75 \%$ & $0.00 \%$ & $0.00 \%$ & $0.00 \%$ & $100.00 \%$ \\
G09 & $0.00 \%$ & $25.00 \%$ & $0.00 \%$ & $75.00 \%$ & $0.00 \%$ & $50.00 \%$ & $0.00 \%$ & $50.00 \%$ \\
G10 & $0.00 \%$ & $29.17 \%$ & $16.67 \%$ & $54.17 \%$ & $0.00 \%$ & $50.00 \%$ & $25.00 \%$ & $25.00 \%$ \\
G11 & $0.00 \%$ & $56.25 \%$ & $0.00 \%$ & $43.75 \%$ & $0.00 \%$ & $12.50 \%$ & $0.00 \%$ & $87.50 \%$ \\
G12 & $0.00 \%$ & $37.50 \%$ & $0.00 \%$ & $62.50 \%$ & $0.00 \%$ & $12.50 \%$ & $0.00 \%$ & $87.50 \%$ \\
G13 & $0.00 \%$ & $12.50 \%$ & $0.00 \%$ & $87.50 \%$ & $0.00 \%$ & $0.00 \%$ & $0.00 \%$ & $100.00 \%$ \\
G14 $35.42 \%$ & $54.17 \%$ & $0.00 \%$ & $10.42 \%$ & $58.33 \%$ & $20.83 \%$ & $0.00 \%$ & $20.83 \%$ \\
G15 & $0.00 \%$ & $81.25 \%$ & $0.00 \%$ & $18.75 \%$ & $0.00 \%$ & $75.00 \%$ & $0.00 \%$ & $25.00 \%$ \\
G16 & $0.00 \%$ & $50.00 \%$ & $0.00 \%$ & $50.00 \%$ & $0.00 \%$ & $50.00 \%$ & $0.00 \%$ & $50.00 \%$ \\
G17 & $0.00 \%$ & $12.50 \%$ & $0.00 \%$ & $87.50 \%$ & $0.00 \%$ & $0.00 \%$ & $0.00 \%$ & $100.00 \%$ \\
G18 & $0.00 \%$ & $0.00 \%$ & $12.50 \%$ & $87.50 \%$ & $0.00 \%$ & $0.00 \%$ & $0.00 \%$ & $100.00 \%$ \\
G19 & $0.00 \%$ & $31.25 \%$ & $0.00 \%$ & $68.75 \%$ & $0.00 \%$ & $0.00 \%$ & $0.00 \%$ & $100.00 \%$ \\
G20 & $0.00 \%$ & $56.25 \%$ & $0.00 \%$ & $43.75 \%$ & $0.00 \%$ & $50.00 \%$ & $0.00 \%$ & $50.00 \%$ \\
\hline \hline
\end{tabular}

The fraction of won election are shown with respect to all elections within a series or considering only the last 4 elections of a series for all 20 groups of the PVFI treatment. G01 to G08 represent the first session and G09 to G20 the second session of the treatment. 
Table 15: Fraction of won election for all 24 groups of the PVNI treatment.

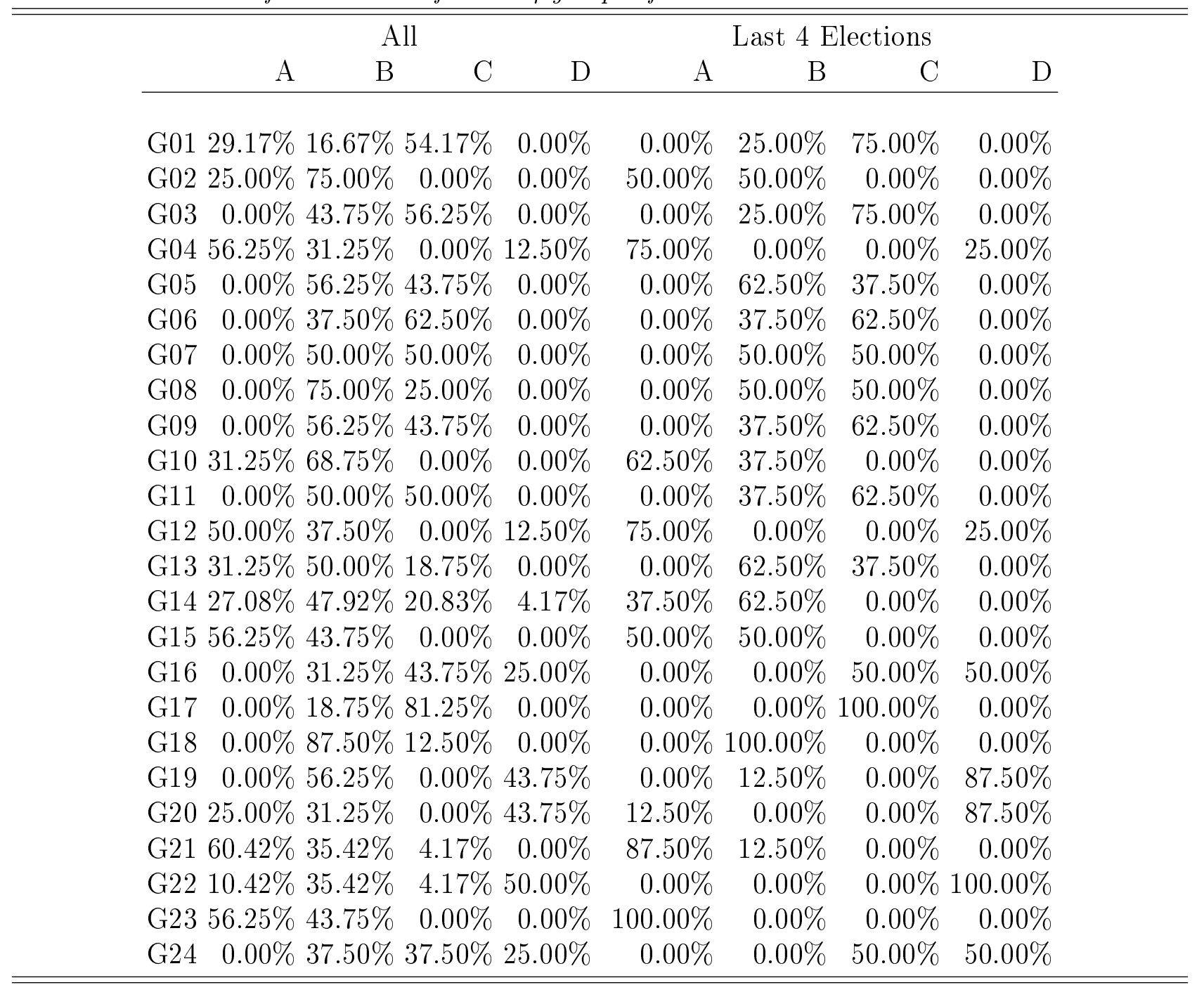

The fraction of won election are shown with respect to all elections within a series or considering only the last 4 elections of a series for all 24 groups of the PVNI treatment. G01 to G12 represent the first session and G13 to G24 the second session of the treatment. 